\title{
Sleep promoting neurons remodel their response properties to calibrate sleep drive with environmental demands.
}

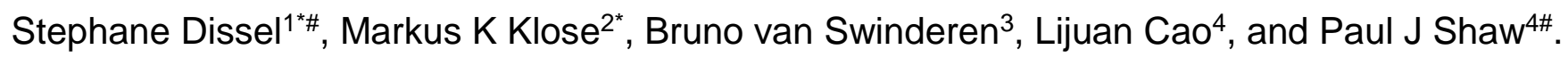

${ }^{*}$ Contributed equally to this work

Affiliations:

${ }^{1}$ Department of Genetics,

Developmental and Evolutionary Biology

School of Biological and Chemical Sciences

University of Missouri-Kansas City

5007 Rockhill Rd.

Kansas City, MO 64110

2University of Pittsburgh School of Medicine

Department of Pharmacology \& Chemical Biology

W1340 Thomas E. Starzl Biomedical Science Tower

200 Lothrop St

Pittsburgh, PA 15261

${ }^{3}$ The Queensland Brain Institute

QBI Building, 79

The University of Queensland

St Lucia QLD 4072, Australia

${ }^{4}$ Department of Neuroscience

Washington University School of Medicine

Campus Box 8108

660 South Euclid Avenue

St. Louis, MO 63110 USA

Ph: 314-362-2703 Fax: 314-362-3446

\# co-Corresponding authors:

shawp@wustl.edu

dissels@umkc.edu 


\section{Abstract}

Falling asleep at the wrong time can place an individual at risk of immediate physical harm. However, not sleeping degrades cognition and adaptive behavior. To understand how animals match sleep need with environmental demands, we used live-brain imaging to examine the physiological response properties of the Drosophila sleep homeostat (dFB) following interventions that modify sleep (sleep deprivation, starvation, time-restricted feeding, memory consolidation). We report that dFB neurons can distinguish between different types of waking and can change their physiological responseproperties accordingly. That is, dFB neurons are not simply passive components of a hard-wired circuit. Rather, the dFB neurons themselves can determine their response to the activity from upstream circuits. Finally, we show that the dFB appears to contain a memory trace of prior exposure to metabolic challenges induced by starvation or time-restricted feeding. Together these data highlight that the sleep homeostat is plastic and suggests an underlying mechanism.

\section{Introduction}

The importance of sleep is highlighted by the observation that it is evolutionarily conserved despite directly competing with all motivated waking behaviors [1, 2]. Not only does sleep compete with foraging, eating and mating [3-6] for example, high sleep drive may be maladaptive in many circumstances since falling asleep could place the individual in danger of immediate physical harm [7, 8]. On the other hand, sleep plays a critical role in learning and memory, supports adaptive behavior and facilitates creative insight. [9-12]. Together these observations suggest that it will not be possible to fully understand sleep's function without knowing how sleep circuits calibrate sleep drive with motivational states.

In recent years, a great deal of progress has been made dissecting circuits that regulate motivated behavior in flies [13-17]. Typically, the properties of a circuit are examined as a function of one internal state. For example, sleep circuits are evaluated after sleep loss [18-20], feeding in response to starvation or high dietary sugar [21,22], thirst following water deprivation [23], mating after social isolation [24] etc. However, since internal states can promote conflicting goal-directed behaviors, recent studies have begun to evaluate how circuits regulate competing activities such as feeding and sleep [5, 25-29], thirst and hunger [23], sweet and bitter taste [30], hunger and mating [31], and thirst vs hunger relevant memory [23], for example.

A common theme that has emerged from these studies has been that a specific deprivation-state differentially activates a subset of peptidergic neurons that then modulate classic neurotransmitter systems, frequently dopamine, to alter downstream circuits and thus motivated behavior [31-33]. For example, water deprivation preferentially activates a subset of peptidergic neurons which inhibit specific dopaminergic neurons to alter thirst-relevant memory [34]. In this model, the competition between state-specific peptidergic neurons will determine which motivated behavior will be expressed. An open question, however, is whether the neurons receiving peptidergic or dopaminergic input are constrained such that their responses are determined by upstream signals, or on the other hand, whether they can change their own response properties over time to influence a given outcome. 
Sleep promoting R23E10 neurons are well suited to investigate these relationships. R23E10 neurons are modulated both by Dopaminergic neurons and Allatostatin-A (AstA)-expressing circadian-neurons $[19,23,25-27,35,36]$. AstA-expressing neurons promote sleep by releasing glutamate onto $R 23 E 10$ neurons [25]. Allatostatin-A is the Drosophila homologue of Galanin and has been implicated in both feeding and sleep [27, 37]. Sleep promoting R23E10 neurons comprise a sleep switch and are an integral part of the sleep homeostat [19, 26]. The intrinsic properties of R23E10 neurons have been evaluated in the context of sleep loss where it seems they monitor redox processes as an indicator of energy metabolism [19, 38, 39]. Thus, R23E10 neurons may serve as command neurons of sorts that can integrate stimuli from competing internal states to gate information flow [40,41]. Both the input and output connections to R23E10 are well documented [25, 26, 35, 36]. Thus, the focus of this study is evaluate sleep promoting R23E10 neurons following challenges that modulate motivational states.

In this study we identify independent sets of heterogeneous sleep-promoting neurons that change their responses to Dopamine and AstA following challenges that influence sleep. In addition, we identify a wake-promoting effect of AstA on R23E10 neurons suggesting that the co-release of inhibitory AstA with excitatory glutamate may attenuate the overexcitement of $R 23 E 10$ neurons during high sleep drive and allow animals to maintain wakefulness in dangerous or life-threatening conditions. Finally, we find that both time-restricted feeding and acute starvation enhance subsequent waking by remodeling the expression of Dopamine receptors in sleep promoting neurons. Together, these data provide new insights into the interaction between internal states and sleep regulation.

\section{Results:}

\section{Neurons projecting to the dorsal Fan Shaped Body are modulated by Allatostatin.}

dFB projecting $R 23 E 10$ neurons are an important component of the sleep homeostat [19, 38, 39]. Sleep promoting dFB neurons are believed to be inhibited by wake-promoting dopaminergic neurons and activated when glutamate is released from sleep-promoting AstA expressing neurons [25, 35, 36]. Surprisingly, the role of AstA on R23E10 neurons has not been investigated. Thus, we used behavioral genetics and live-brain imaging to characterize the effects of AstA and Dopamine on R23E10 neurons. The expression pattern of R23E10 neurons is shown in Figure 1a. Expressing the temperature-sensitive Transient receptor potential cation channel (UAS-TrpA1) in R23E10 neurons and raising the temperature from $25^{\circ} \mathrm{C}$ to $31^{\circ} \mathrm{C}$ for $6 \mathrm{~h}$ increased sleep (Figures $1 \mathrm{~b}, \mathrm{c}$ ). The parental controls do not show an increase in sleep during the exposure to $31^{\circ} \mathrm{C}$ (Figure S1). Since many neuromodulators act through second messenger signaling cascades, we expressed the cyclic adenosine monophosphate (cAMP) sensor, UAS-Epac1-camps, in R23E10 neurons and used high throughput live-brain imaging to monitor neuronal responses to bath applied Dopamine (Figure 1d) [42, 43]. As seen in Figure 1e, DA increases cAMP levels in dFB neurons as previously reported [36]. It is important to note that while R23E10>GFP identifies $\sim 14$ neurons/hemisphere, R23E10>UASEpac1-camps reliably labeled $\sim 8$ neurons/hemisphere. Thus, we have confirmed that R23E10 neurons are sleep promoting and respond to Dopamine. 
Given that R23E10 neurons are downstream of AstA-expressing neurons [25], we evaluated the response properties of $R 23 E 10$ neurons to AstA and 14 other compounds that can influence motivational states [44]. As seen in Figure $1 \mathrm{f}, \mathrm{g}$, AstA reduced cAMP levels in R23E10 neurons. Previous studies indicate that AstA is an inhibitory peptide [45]. Individual traces for Figure $1 \mathrm{~g}$, are plotted in Figure S2a. Consistent with the cAMP responses, knocking down a battery of neuropeptide receptors in R23E10 neurons using RNAi did not substantially modify sleep (Figure S2b). To determine whether the effects of AstA on R23E10 neurons are direct, we incubated brains in Tetrodotoxin (TTX), which inhibits the firing of action potentials. TTX does not prevent the AstA mediated cAMP response of $R 23 E 10$ cells (Figure $1 \mathrm{~h}$, green trace). To further confirm a direct role of AstA we used RNA interference (RNAi) to knock down the AstA-R1 receptor in R23E10 neurons. As seen in Figure $1 \mathrm{~h}$ (red trace), the cAMP response triggered by application of AstA is attenuated. Quantification of these effects are shown in Figure 1i. Importantly, R23E10 neurons responded normally to DA when AstA-R1 levels are knocked-down indicating that the reduced response to AstA is not the result of a non-functional neuron (Figure S2c).

To better understand the relationship between AstA and R23E10 neurons we used immunohistochemistry to evaluate the overlap between AstA and AstA-GAL4. As previously reported, AstA-GAL4 does not fully recapitulate the AstA expression pattern within the projections to the dFB (Figures 1j -j") [37]. Nonetheless, AstA-GAL4 is expressed near the dendritic fields of R23E10 suggesting a physical connection between the two group of neurons (Figures 1k-k")[25]. To evaluate functional connectivity of the AstA-GAL4, R23E10 circuit, we expressed the P2X2 activator [46] in AstA-GAL4 neurons while measuring cAMP with LexAop-Epac in R23E10-LexA neurons. As seen in Figures $11, \mathrm{~m}$, perfusion of ATP which activates $P 2 X 2$, leads to a reduction of cAMP levels in R23E10 cells, mimicking the effect of AstA on R23E10 neurons reported above (Figure 1f). No changes in cAMP signaling were observed in parental controls perfused with ATP but that do not express $P 2 X 2$ indicating the effects are specific to the activation of AstA-GAL4 neurons (Figure 11, red trace). Thus, we show that the cAMP response of R23E10 neurons to AstA is similar to that seen when AstA expressing cells are activated.

The sleep promoting effects of AstA-expressing neurons have been shown to be due to the release of glutamate onto R23E10 neurons [25]. Since AstA is an inhibitory neuropeptide [44, 45], we would predict the impact of AstA on R23E10 neurons would be wake-promoting and that knocking down AstARs would thus increase sleep. To test this hypothesis, we evaluated sleep after knocking down AstAR1 and AstAR2 in R23E10 neurons. As seen in Figures 2a,b and 2e,f, total sleep is increased when $A s t A-R 1$ or $A s t A-R 2$ are knocked down in R23E10 neurons, suggesting that the $\mathrm{dFB}$ is under consistent allatostatinergic inhibitory tone. Importantly, sleep is also more consolidated during the day (Figures 2c,g); sleep consolidation is also increased at night (Figures S3a,b). Furthermore, the latency to fall asleep at night is reduced (Figures S3 c,d). The increase in sleep is not due to unhealthy or sick flies since waking activity is not reduced compared to parental controls (Figures $2 \mathrm{~d}$, h). To rule out off-target effects of the single RNAi line, we tested three additional, independent AstA$R 1$ RNAi lines, and found that sleep is significantly increased in each line (Figure S3e). Given that increasing the activity of AstA neurons has been reported to increase sleep, but the R23E10 $>A s t A R^{R N A i}$ data indicate that AstA provides a wake signal, we asked whether our results might be due to unknown environmental factors in our laboratory. To evaluate this possibility, we utilized two lines (AstA-GAL4 and R65D05-LexA) that express in AstA-expressing clock neurons and 
increase sleep [25]. As seen in Figure S3f, both AstA-GAL4-dTrpA1 and R65D05-LexA>LexAop$d T r p A 1$ lines substantially increased sleep consistent with previous reports [25]. Since AstA is an inhibitory neuropeptide, and the mammalian homologue of $A s t A-R 1$ signals mainly through the $\mathrm{Gi}$ pathway [47], we hypothesized that the AstA receptors might be coupled to inhibitory $G$ protein subunits. To test this hypothesis, we used RNAi to knockdown specific G protein subunits in sleeppromoting dFB neurons. As seen in Figure 2i, knocking down Goa47A had no effect on sleep while knocking down Gia65A using two different RNAi lines significantly increased sleep. Furthermore, independently knocking down $\beta$ and $\gamma_{1}$ subunits in sleep-promoting R23E10 neurons also increased sleep (Figure 2i). Thus, these data suggest that AstA may be inhibiting dFB neurons via coupling with inhibitory $\mathrm{G}$ proteins.

\section{Sleep promoting dFB are diverse.}

Dorsal Fan Shaped Body neurons (dFB) have been hypothesized to gate different aspects of sleep such as locomotion, sensory thresholds etc. [26, 48]. This hypothesis suggests that the dFB could be comprised of independent sets of sleep promoting neurons that each respond to distinct environmental challenges. If this were to be the case, then we should be able to identify novel dFB projecting GAL4 lines. To expedite the identification of such lines, we asked Dr. Gerry Rubin and Dr. Arnim Jenett, for assistance [49]. They hand-selected 12 GAL4 lines that matched the expression pattern of the original sleep promoting GAL4 lines (104y and C5) [10]. We activated these neurons by expressing UAS-TrpA1 as described above. Surprisingly, only one driver, R55B01 increased sleep similarly to $R 23 E 10$ when compared to siblings maintained at $25^{\circ} \mathrm{C}$ (Figures 3 a,b and Figure S4). The parental controls do not show an increase in sleep during the $6 \mathrm{~h}$ exposure to $31^{\circ} \mathrm{C}$ (Figure $\mathrm{S} 1$ ). Similar results were obtained when expressing the sodium bacterial channel, UAS-NaChBac (data not shown). As seen in Figure 3c, R55B01 project to the dFB neuropil (blue arrow) and have cell bodies located in the same anatomical region in the brain as R23E10 neurons. To determine potential overlap between $R 23 E 10$ and R55B01, we conducted co-labeling experiments to express RFP with GAL4/UAS and GFP with LexA/LexAop in the same fly. As seen in Figures S5c-c",d R23E10-LexA is similar, but not identical, to the expression pattern of R23E10-GAL4. Importantly, R23E10-LexA and R55B01-GAL4 only share $\sim 4$ neurons in common (Figures S5 a-a",b). As with R23E10 neurons, R55B01> UAS-Epac1-camps labels fewer dFB projecting neurons ( 8 neurons) compared to R55B01>GFP. Similar to R23E10 neurons, R55B01>UAS-Epac-camps show robust responses to AstA (Figure 3d). Moreover, AstA positive staining is co-localized with the GFP positive processes of R55BO1 neurons (Figures S5e-e'"). In contrast to R23E10 neurons, the response of R55B01 neurons to dopamine is either reduced or absent (Figure 3e). A box plot comparing the range of responses of R23E10 and R55B01 neurons to dopamine is shown in Figure 3f. Given the robust responses of R55B01 neurons to AstA, we evaluated sleep after knocking down AstAR1 and AstAR2. As seen in Figures $3 \mathrm{~g}$,h sleep is increased upon knocking down either AstAR1 or AstAR2 in R55B01 neurons. Quantification of sleep architecture in R55B01>AstAR ${ }^{1{ }^{R A i}}$ and $R 55 B 01>A s t A R 2^{R N A i}$ can be found in Figure S6. Thus, we have identified an additional sleep promoting driver that projects to the dFB, has little overlap with R23E10 neurons and is less responsive to dopamine.

\section{R23E10 neurons differentially integrate sleep-relevant stimuli.}


Together with the literature, these data identify two major wake-promoting signals that impact R23E10 neurons; AstA and Dopamine [35, 36]. Although both signals are inhibitory, they derive from neuronal circuits with opposite functions; AstA is released from sleep promoting neurons while Dopamine is released from wake-promoting neurons [25, 35, 36]. Given these divergent roles, we hypothesize that AstA and Dopamine will operate largely independently. To test this hypothesis, we used the live-brain imaging approach described above (Figure 1d) to evaluate the response of R23E10 neurons to either Dopamine or Allatostatin during conditions that alter sleep drive. Since R55B01 neurons respond less to Dopamine, we focused solely on R23E10 neurons; R55B01 neurons will be studied later. We first evaluated the response properties or R23E10 neurons in unperturbed flies under conditions characterized by large changes in sleep time (e.g. ontogeny, gender, individual differences). We then evaluated the response properties of R23E10 neurons after experimental interventions that modulate sleep drive (e.g. sleep loss, starvation, training that induces long-term memory) [3, 28, 50-53] (Figure 4). Quantification of traces in Figure 4 can be found in Figure S7).

As with humans, sleep is highest in young flies and then stabilizes in early adulthood. Interestingly, R23E10 neurons are less responsive to Dopamine in 0-1day old flies compared to 6-8 day old mature adults; no changes were observed in response to AstA (Figures 4a,b). The response properties of R23E10 neurons to Dopamine were similar in 6-8 day old flies and 30-38 day old flies (Data not shown). In contrast to age, we did not observe any changes in the response properties of R23E10 neurons in male and female flies despite large sexual dimorphisms in sleep behavior [52, 54] (Data not shown). We have previously shown that individual differences in sleep time can be exploited to evaluate sleep regulation and function [55]. Importantly, our previously published data indicate that spontaneously short-sleeping flies appear to experience both high wake-drive and high sleep-drive simultaneously [56]. With that in mind, we evaluated the response properties of R23E10 neurons in spontaneously short-sleeping R23E10>UAS-Epac-camps1(i.e. total sleep time less than 400min) compared to normal sleeping siblings (800-960 min sleep). As seen in Figure 4c, R23E10 neurons appear to be under stronger inhibitory tone from AstA in spontaneous short-sleepers compared to normal sleeping siblings. Although one would predict a stronger response of $R 23 E 10$ neurons to the wake-promoting effects of Dopamine, short sleeping flies were less responsive to Dopamine (Figure 4d). Future studies will be needed to determine whether incongruent responses of R23E10 neurons to AstA and Dopamine reveal underlying deficits in sleep regulation.

We next asked whether distinct experimental interventions that modulate sleep drive would alter the physiological response properties of R23E10 neurons in similar or dissimilar ways. Both sleep deprivation and extended periods of starvation are followed by a compensatory increase in sleep [3, $28,57]$. To evaluate how sleep disruption would influence $R 23 E 10$ neurons, flies were sleep deprived for $12 \mathrm{~h}$ or starved for $18 \mathrm{~h}$ and compared to untreated siblings. As seen in Figure 4e, cAMP responses to AstA are increased following sleep deprivation but were unchanged in response to Dopamine (Figure 4f). Surprisingly, the response of R23E10 neurons to either AstA or Dopamine were not changed while being starved (Figures $4 \mathrm{~g}, \mathrm{~h}$ and see below). In contrast to sleep deprivation and starvation, social enrichment induces plasticity in specific neural circuits to increase sleep without exposing flies to sleep loss [51, 58]. Changes in sleep following social enrichment have been mapped to pigment dispersing factor (PDF) expressing clock neurons [58]. Interestingly, AstA signaling is modulated by PDF [27]. Thus, to evaluate the impact of social rearing we housed flies in a socially 
enriched environment (50 flies/vial) for 5 days and evaluated cAMP responses compared to isolated siblings. As seen in Figure 4i, R23E10 neurons of socially enriched or isolated flies show similar responses to AstA. However, DA responses of R23E10 cells are strongly reduced by social enrichment (Figure 4j). These data demonstrate that disparate behavioral manipulations that increase sleep drive in different ways induce independent physiological responses of $R 23 E 10$ neurons to AstA and DA.

Sleep dependent memory consolidation has been linked to both the ventral and dorsal Fan Shaped Body [10,59]. Thus, we asked whether R23E10 neurons would modify their physiological responses to a training protocol that induces LTM [9]. As seen in Figure 4k, responses of $R 23 E 10$ neurons to Ast $A$ are not different following courtship conditioning. However, training resulted in a dramatic reduction in the response of R23E10 neurons to DA (Figure 4I). Interestingly, the effect of training on DA responses could still be observed $24 \mathrm{~h}$ after the end of the training only returning to baseline $48 \mathrm{~h}$ later suggesting long-term plastic changes in R23E10 neurons (Figure S7m). To determine whether the changes in CAMP were due to non-specific effects of courtship or to memory consolidation, we evaluated cAMP levels following a massed training protocol consisting of a single $3 \mathrm{~h}$ session that does not result in LTM formation [10]. As seen in Figure S7m, massed training did not alter the responses of R23E10 cells to Dopamine. Furthermore, no changes in responses to Dopamine were found when training was followed by $4 \mathrm{~h}$ of sleep deprivation (data not shown). To further evaluate the role of the dFB in courtship memory, we used CaLexA (calcium-dependent nuclear import of LexA) to see if R23E10 neurons might show sustained activity following a spaced training protocol [60]. R23E10 flies expressing CaLexA were exposed to a training protocol consisting of $3 \times 1 \mathrm{~h}$ individual pairings of a naïve male with a non-receptive female target separated by a rest period of 1h. As seen in Figure 4m, sleep is increased following training compared with non-trained siblings consistent with previous reports [51, 58]. R23E10 neurons show higher GFP signal in trained animals when assessed the following morning compared with their naïve counterparts indicating that sleeppromoting neurons are more active following courtship memory training (Figures $4 \mathrm{n}$ and $4 \mathrm{o}$ for quantification). Together these data indicate that the response properties of $R 23 E 10$ neurons display long-lasting changes following protocols that induce LTM.

\section{Prior feeding experience alters the recruitment of Dopamine receptors to modulate sleep.}

Initial studies indicated that the wake promoting effects of Dopamine on dFB neurons are mediated by the Dopamine 1-like receptor 1 (Dop1R1) [35, 36, 61]. However, the role of the Dop1R1 has been called into question [19]. We have recently shown that the constellation of receptors expressed on a neuron can be altered by starvation to include a receptor that is not typically present [3]. Specifically, our data suggest that the new receptor is recruited to amplify wake-promoting signals in clock neurons to allow animals to engage in adaptive waking behaviors. To determine whether the phenomenon of recruiting new wake-promoting receptors to a neuron will generalize to the $\mathrm{dFB}$, we re-examined the role of the Dop1R1 in R23E10 neurons. In addition, we also evaluated $R 55 B 01$ neurons because these cells have a limited response to Dopamine. We hypothesized that if the Dop1R1 is needed to support waking following a metabolic challenge, knocking it down would manifest as an increase in sleep. Since $18 \mathrm{~h}$ of starvation did not change the response properties of R23E10 neurons (Figures 4g,h), we used time-restricted feeding to safely impose a greater and more sustained metabolic challenge to the fly [62-64]. That is, time-restricted feeding should provide a 
substantial metabolic challenge but should not result in lethality. The time-restricted feeding protocol is shown in Figure 5a. Flies are only given access to food between $8 \mathrm{am}$ and $5 \mathrm{pm}$ for a total of 7 days (restricted). After time restricted feeding, flies are placed into Trikinetics tubes where they were allowed to eat ad lib while sleep is evaluated. Siblings that were maintained in vials with standard food available ad lib and flipped at the same times as their restricted counterparts served as treatment controls (Figure 5a). Consistent with previous reports [19, 36], knockdown of Dop1R1 in R23E10 neurons did not alter sleep in flies that were able to feed ad lib (Figures 5b,d,e). Similarly, no changes in sleep were observed in untreated $R 55 B 01>D o p 1 R 1^{R N A i}$ flies (Figures $5 \mathrm{c}, \mathrm{d}, \mathrm{e}$ ). However, both $R 23 E 10>D o p 1 R 1^{R N A i}$ and 55B01>Dop1R1 ${ }^{R N A i}$ flies displayed dramatic increases in sleep following 7 days of time-restricted feeding compared to their R23E10/+, 55B01/+ and Dop1R1RNAi /+ parental controls (Figures $5 f-i)$. These data are consistent with the hypothesis that, under certain circumstances, a new receptor can be recruited to amplify wake-promoting signals.

Time restricted feeding is characterized by defined intervals of feeding and fasting. Thus, during timerestricted feeding, the Dop1R1 may be recruited to R23E10 neurons to either support waking during starvation or to support waking when food is available. To distinguish between these possibilities, we

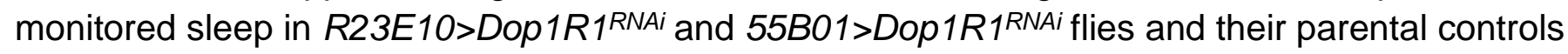
during baseline, during $18 \mathrm{~h}$ of starvation and for three days after being placed back onto food (Figures 6a,b). As above, no changes in baseline sleep were observed while knocking down Dop1R1 in either R23E10 or R55B01 neurons compared to parental controls (Figures 6a,b,c,d). Moreover, $R 23 E 10>D o p 1 R 1^{R N A i}$ and 55B01>Dop1R1RNAi flies exhibited similar sleep patterns to parental controls during starvation (Figure S8a). However, during recovery following $18 \mathrm{~h}$ of starvation, an increase in sleep was observed in both $R 23 E 10>D o p 1 R 1^{R N A i}$ and 55B01>Dop $1 R 1^{R N A i}$ flies compared to their respective parental controls (Figures 6a,b). It is important to highlight that sleep in the experimental lines only diverged from their parental controls after several hours, or more, of recovery (Figures 6a,b arrows). Quantification of sleep during Recovery day 1 and Recovery day 2 is shown in Figures S8b,c. Sleep stabilized in both $R 23 E 10>D o p 1 R 1^{R N A i}$ and 55B01>Dop $1 R 1^{R N A i}$ flies on the third day of recovery and remained elevated for several days thereafter (Figures $6, a, b, e$ and data not shown). Thus, these data indicate that the Dop1R1 is recruited to $R 23 E 10$ and $R 55 B 01$ neurons to support waking behavior during recovery from starvation.

To gain additional insight into the physiological impact of starvation, we used live-brain imaging to evaluate the responses of R23E10>Epac; UAS-Dop1R2RNAi and R55B01>Epac; UAS-Dop1R2RNAi to Dopamine under baseline and on recovery day 2 from starvation. While both Dop1R1 and Dop1R2 couple to Gas, Dop1R2 appears to also activate Gaq [65]. We hypothesized that knocking down Dop1R2 would reduce the response of R23E10 neurons to dopamine under baseline conditions and that the neurons would respond to Dopamine following 2 days of recovery from starvation. R23E10>UAS-Dop1R2RNAi flies displayed an increase in sleep under baseline conditions consistent with previous reports (data not shown)[19]. As seen in Figures 7a,b R23E10>Epac; UAS-Dop1R2RNAi neurons did not show a strong response to Dopamine during baseline. However, during recovery from starvation $R 23 E 10>E p a c ;$ UAS-Dop1R2 ${ }^{R N A i}$ neurons exhibited a significant increase in their response to Dopamine suggesting a new receptor is added (Figures 7a,b). Next we evaluated the effects of starvation on R55B01 neurons. As seen in Figures 7c,d neither R55B01>Epac nor R55B01>Epac;UAS-Dop1R2RNAi responded to Dopamine under baseline conditions. Although much smaller than that observed for R23E10 neurons, R55B01>Epac;UAS-Dop1R2RNAi neurons did 
respond modestly to Dopamine after two days of recovery from starvation (Figures 7c,d). While we cannot exclude a role of other Dopamine receptors (e.g. Dopamine/Ecdysteroid receptor) for the observed changes, when viewed with the sleep experiments shown above (Figures 5 and 6), these data suggest that during recovery from starvation the constellation of Dopamine receptors in R23E10 and $R 55 B 01$ changes and most likely includes the recruitment of Dop1R1. These data provide new insights into the mechanisms used by sleep-circuits to link internal states and prior waking history with sleep need.

\section{Discussion}

In this work we ask whether the activity of sleep-promoting dFB neurons reflects the summation of their upstream inputs in a winner-take all strategy, or if they can change their own response properties to influence how environmental demands alter behavioral state. Although one possibility does not preclude the other, our data indicate that both time-restricted feeding and $\sim 18 \mathrm{~h}$ of starvation, alter the constellation of Dopamine receptors expressed by R23E10 and R55B01 neurons. These results emphasize that the ability of upstream circuits to alter behavior will not only depend upon the strength of the incoming signals but also the recent historical context of R23E10 and R55B01 neurons themselves. In that regard, it important to note that while sleep competes with all motivated waking-behavior, the proper regulation of motivated behaviors degrade in the absence of sleep [50, 66-74]. Together these observations suggest that it will not be possible to fully understand sleep's function without knowing how sleep-promoting neurons alter their functional properties to prioritize conflicting motivational states.

\section{The dFB is comprised of independent sets of sleep promoting neurons}

Previous studies indicate that the dFB can independently gate different aspects of sleep [26]. Moreover, the expression of the gap junction innexin6 in R23E10 neurons is required to gate sensory thresholds and sleep time[48]. Together these data suggest the presence of independent sets of dFB neurons. Although we screened through a refined set of hand selected GAL4 lines that project into the dFB in a manner similar to $104 y-G A L 4$ and C5-GAL4 [10, 49], we only identified one additional GAL4 line, R55B01, that reliably increased sleep when crossed with UAS-dTrpA1. Similar results were obtained when activating the neurons using the bacterial sodium channel UAS-NaChBac. This latter result is relevant given that sleep is modulated by temperature and that GABAergic neurons projecting onto dFB regulate temperature-dependent changes in sleep [75, 76]. We also identified dFB projecting GAL4 lines that increased waking. However, the precise role that these GAL4 lines play in waking awaits additional inquiry. Nonetheless, these data suggest that sleep promoting dFB neurons are limited in number. It should be noted that the extent of the overlap between $R 23 E 10$ and $R 55 B 01$ remains unclear as the R23E10-LexA driver does not fully recapitulate the R23E10-GAL4 expression patterns (Figure S5). Although it may be possible to subdivide R23E10 and R55B01 neurons further, our data suggest that there are at least two independent sets of sleep promoting neurons that have projections into the dFB (see below for additional discussion). In mice, sleep promoting neurons are also diverse as assessed by their role in regulating behavior and their projection patterns [77].

\section{Allatostatin inhibits sleep-promoting neurons}


Although AstA-expressing neurons are believed to promote sleep by releasing glutamate onto R23E10 neurons [25], our data identify a wake-promoting effect of AstA on R23E10 neurons. Specifically, we find that knocking down either the AstAR1 or AstAR2 in R23E10 or R55B01 neurons using several independent RNAi lines results in a substantial increase in sleep. The observation that knocking down either the AstAR1 or AstAR2 in R23E10 neurons increases sleep, suggests that R23E10 neurons are under constant inhibitory tone from AstA and that both receptors play an important role in modulating sleep in untreated flies. In addition, we report that the application of $1 \mathrm{mM}$ ATP to R23E10>Epac; AstA-GAL4>P2X2 neurons reduces cAMP levels similarly to that observed with application of AstA. Although our data appear to be in conflict with that of $\mathrm{Ni}$ and colleagues, we hypothesize that the co-release of inhibitory AstA with excitatory glutamate may attenuate the overexcitement of R23E10 neurons during high sleep drive and allow animals to maintain wakefulness in dangerous or life-threatening conditions.

In support of this hypothesis, a growing body of evidence indicates that sleep and wake regulating neurons co-release different transmitters and neuropeptides to better match sleep-need with environmental demands [78]. Indeed, it has been suggested that antagonistic neurotransmitter corelease may both prevent excessive excitation of postsynaptic targets and increase the flexibility of neuronal networks [45, 78, 79]. For example, the co-release of GABA by histaminergic tuberomammillary nucleus is believed to prevent histamine-induced overexcitement of downstream circuits and thereby better support normal amounts of waking [80]. Similarly, the co-release of galanin by noradrenergic neurons is believed to prevent overexcitement of locus coeruleus[81]. Although the co-expression of AstA and glutamate has been established [25, 82], our data reveal a new mechanism for how incompatible motivational drives can be regulated.

An alternate possibility to explain the wake-promoting effects of AstA on R23E10 and 55B01 neurons may be that $R 23 E 10$ and $R 55 B 01$ are, in fact, a heterogeneous sets of neurons which also include wake promoting neurons and/or neurons whose primary role is to promote active sleep at the expense of deep sleep [83]. Active sleep is best observed following $24 \mathrm{~h}$ of sleep deprivation and is associated with dramatic reductions in the response to external sensory stimuli. If AstA were to inhibit a subset of $R 23 E 10$ that promote active sleep, one would predict an increased deep sleep. The diversity in the responses to Dopamine seen in both R23E10 and R55B01 neurons (Figure 3f) further supports the hypothesis that these GAL4 lines express in heterogeneous set of neurons with different functions; a previous study has found similar heterogeneity in $R 23 E 10$ neurons. [38]. Alternatively, it is possible that AstA does not inhibit the R23E10 neurons per se but rather alters temporal spike patterns to favor active-sleep or deep-sleep in a manner similar to that observed in clock neurons [84]. Indeed, AstA has been shown to alter the spike-timing precision of mechanoreceptor afferents in Carcinus maenas and the mammalian homologue of AstA, Galanin, alters spontaneous spike firing in rodents $[85,86]$. These possibilities will be explored in future studies.

It is important to note that neuropeptides are notoriously pleiotropic and also work as neurohormones [44]. Thus, it is possible that additional sleep and wake promoting circuits downstream of AstA-GAL4 or 65D05-GAL4 will be found elsewhere in the brain. It is interesting to note that neurons expressing the mouse homologue of AstA, galanin, also regulate conflicting behaviors [77]. Specifically, Galanin expressing neurons that project to the tuberomammillary nucleus promote sleep while Galanin 
expressing neurons that projection to the medial amygdala promote parental behaviors [77, 87, 88]. Thus it will be important for future studies to discern how AstA and galanin circuits regulate competing activities in other circuits.

\section{R23E10 neurons differentially encode arousal signals.}

Increased sleep drive may be maladaptive in many circumstances since falling asleep could place the individual in danger of immediate physical harm $[7,8]$. Increased sleep also competes with important waking behaviors such as foraging, eating and mating [3,4]. However, sleep plays a critical role in learning and memory, supports adaptive behavior and facilitates creative insight [9-12]. How do sleep promoting neurons distinguish between competing drives? Our live-brain imaging data suggest the intriguing possibility that R23E10 neurons can distinguish between different types of waking and change their response properties accordingly. Specifically, R23E10 neurons selectively decrease their response to the wake-promoting effects of Dopamine following conditions that promote plasticity. In contrast, R23E10 neurons increase their response to the wake-promoting effects of AstA during conditions when sleep drive is high but the expression of sleep might be dangerous (e.g. during sleep deprivation). Finally, R23E10 neurons appear to contain a memory trace of starvation as evidenced by the increase inhibitory tone conveyed by the recruitment of the Dop $1 R 1$. Thus, R23E10 neurons are plastic and can utilize AstA and DA in very different ways to favor specific behavioral outcomes.

As mentioned, increasing inhibitory signals onto sleep promoting neurons during sleep deprivation may be an adaptive response that allows animals to stay awake despite increasing sleep drive. Indeed, lesioning Galanin neurons in the preoptic area reduces sleep rebound following sleep loss in mice [89]. However, AstA is also reported to be a satiety signal that limits feeding [27, 32, 37, 90]. The effects of Ast $A$ on feeding seem to be in conflict with the studies linking sleep deprivation to increased food intake [91-94]. Nonetheless, recent reports have identified complex interactions between hunger and satiety signals that may be nutrient specific and can be modified by Hebbian plasticity [32, 34, 40,44]. Thus, it is reasonable to expect that sleep deprivation must differentially activate neurons regulating a variety of motivated behaviors including satiety and sleep drive. Indeed, these data indicate that sleep deprivation may be harnessed as a tool to further explore how internal states impact neuronal circuits regulating conflicting goal-directed behaviors [30].

\section{R23E10 neurons support Long Term Memory}

Interestingly, the ventral Fan Shaped body (vFB) promotes sleep and regulates the activity of Dopaminergic aSP13 neurons (DAN-aSP13s) to consolidate long-term memory as assessed using courtship conditioning [59]. Surprisingly, activating R23E10 neurons does not alter the activity of DAN-aSP13s neurons suggesting that the dFB may not be involved in courtship memory [59]. It should be noted, however, that R23E10 neurons regulate the activity of other sets of arousal promoting neurons including the MV1 Dopaminergic neurons and octopaminergic arousal neurons $[25,95]$. These data suggest that the dFB and vFB may play distinct roles in different memory assays. Nonetheless, our data clearly indicate that R23E10 neurons change their response properties following training that induces LTM but not massed training. Importantly, the changes in R23E10 neurons only return to baseline $48 \mathrm{~h}$ after training. It is possible that $R 23 E 10$ neurons play an important, yet indirect, role in courtship memory. That is, activating R23E10 neurons strongly 
suppresses the response to external sensory stimuli $[48,83]$. Thus the activity of R23E10 neurons may protect sleep by limiting the opportunity for external stimuli to wake the animal up. Under this scenario, dFB and vFB neurons would work in concert to carry out sleep functions.

In addition, we find that courtship conditioning increases the activity of R23E10 neurons as assessed by CaLexA. Consistent with this observation, spaced-training reduced the inhibitory effects of Dopamine on R23E10 neurons. Importantly massed-training, which only induced short-term memory, does not alter the response of R23E10 neurons to Dopamine. A previous report has shown that the ectopic expression of Dop1R1 in dFB neurons reduces sleep and fails to rescue courtship conditioning memory in Dopamine transporter mutants $(\mathrm{fmn})$ [36]. Together these data emphasize that reducing Dopaminergic signaling to the dFB neurons is important for long-term memory following courtship conditioning.

\section{Internal state remodels dopamine receptors in sleep promoting neurons.}

The arousal promoting properties of Dopamine projections to the dFB are well established [19, 25, $35,36,61]$. However, which Dopamine receptor is responsible for the increased waking remains controversial. Initial results, using the ectopic expression Dop1R1 and live-brain imaging implicated the Dop1R1 [35, 36]. Nonetheless, RNAi knockdown of Dop1R1 in dFB neurons did not alter sleep [35]. A subsequent study demonstrated that activation of the Dop1R2 results in a transient hyperpolarization of dFB neurons followed by a lasting suppression of excitability lasting minutes; knocking down the Dop1R2 but not Dop1R1 altered sleep [19]. Our data replicate previous RNAi studies that have failed to observe a change in sleep following the expression of Dop1R1 ${ }^{R N A i}$ in $\mathrm{dFB}$ neurons in untreated flies. Indeed, no changes in FRET signal were observed upon the bath application of Dopamine to untreated R23E10>UAS-EPAC; Dop1R2RNAi or R55B01>UAS-EPAC; $D o p 1 R 2^{R N A i}$ flies further supporting the role of Dop1R2 in baseline sleep regulation.

However, in the context of time-restricted-feeding and starvation, knocking down the Dop1R1 in R23E10 and R55B01 neurons resulted in substantial increases in sleep. We hypothesize that both time-restricted feeding and starvation place energy saving sleep-drive in conflict with a metabolic signal that facilitate motivated waking behavior. Increased wake-drive would allow the animals to be more alert and productive during their primary wake-period. Under these circumstances, the Dop $1 R 1$ would be recruited to provide additional inhibitory tone to sleep promoting R23E10 and R55B01 neurons during the light period. Interestingly, starvation results in the recruitment of the Pigment dispersing factor receptor (Pdfr) into wake-promoting large ventrolateral neurons (ILNvs) to facilitate waking at the end of the biological day [3]. Whether other sleep and wake-promoting circuits are regulated in a similar fashion is an open question that will require additional inquiry.

\section{Conclusions}

Given the important roles that Dopamine and AstA play in regulating motivated behaviors, including sleep, we studied their impact on a subset of sleep promoting neurons. Our data reveal that the corelease of AstA is wake promoting and likely serves to maintain waking during periods of high sleep drive. In addition, our data reveal that time-restricted feeding and $18 \mathrm{~h}$ of starvation recruits the Dop1R1 to sleep promoting neurons to maintain wakefulness during the day. These results are 
consistent with our previous data showing that the wake-promoting ILNvs recruit the Pdfr following sleep loss to facilitate waking and that wing-cut reactivates a developmental sleep circuit [3, 96]. The ability of sleep and wake promoting neurons to alter their own physiology, including the recruitment of a new receptor, provides important clues into sleep regulation and function.

\section{Methods.}

\section{Flies}

Flies were cultured at $25^{\circ} \mathrm{C}$ with $50-60 \%$ relative humidity and kept on a diet of yeast, dark corn syrup and agar under a 12-hour light:12-hour dark cycle. R23E10-GAL4; R55B01-GAL4; R33E06-GAL4; R19C06-GAL4; R28H10-GAL4; R09D11-GAL4; R26B11-GAL4; R84C10-GAL4; R58G11-GAL4; R24E05-GAL4; R65C03-GAL4;R12D12-GAL4 and LexAop-TrpA1 were a kind gift from Dr Gerald Rubin at Janelia Farms Research campus. AstA-GAL4; R65D05-LexA; R23E10-LexA; UAS-Dcr2; UAS-TrpA1; UAS-GFP; UAS-RFP, LexAop-GFP; AstA-R1'RNAiJF02578; AstA-R2RNAiJF01955; Goa47ARNAi HMS01129; Gia65ARNAi GL00328; Gia65ARNAi HMS01273; Gß5RNAi JF02941; GB13FRNAi JF01609; GB76CRNAi JF03127; Gy1RNAi HMS01361 ; UAS-Dop1R1-RNAi62193; UASDop1R2RNAi51423; UAS- FMRFaR RNAi25858; UAS-Dh44-R2 RNAi29610; UAS-MsR1RNAi27529; UAS-Dh44-

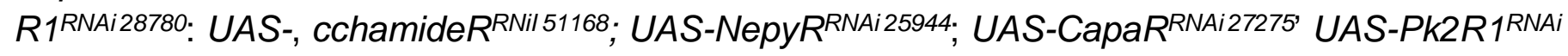
29624; UAS- CCKLR-17D1RNAi 67865; UAS-DH31RRNAi 25925: UAS-AstC-R1RNAi 27506; UAS-TkR99DRNAi 27513: UAS-MsR2RNAi 25832; UAS-LkrRNAi 25936; UAS-CrzRRNAi26017; UAS-ProcR RNAi29414 were obtained from the Bloomington stock center. UAS-Epac1.camps was obtained from Paul Taghert (Washington University in St. Louis). UAS-P2X2 and LexAop-Epac1.camps were a kind gift from Orie Shafer (City University of New York). AstA-R1RNAiv39221 and AstA-R1RNAiv3400 were obtained from the Vienna Drosophila RNAi stock center (Austria). AstA-R1RNAiHMJ21471 was obtained from the Kyoto Drosophila stock center (Japan). CaLexA flies were obtained from Jin Wang (UCSD).

\section{Sleep}

Sleep was assessed as previously described [52]. Briefly, flies were placed into individual $65 \mathrm{~mm}$ tubes containing the same food as they were reared on. All activity was continuously measured through the Trikinetics Drosophila Activity Monitoring System (www.Trikinetics.com, Waltham, Ma). Locomotor activity was measured in 1-minute bins and sleep was defined as periods of quiescence lasting at least 5 minutes. All sleep experiments were replicated a minimum of two times.

\section{Sleep Deprivation}

Sleep deprivation was performed as previously described [50,73]. Briefly, flies were placed into individual $65 \mathrm{~mm}$ tubes and the sleep-nullifying apparatus (SNAP) was used to sleep deprive these flies for 12 hours during the dark phase (lights out to lights on).

\section{Starvation, Time-Restricted Feeding}


For starvation, flies were individually placed into Trikinetics tubes containing the same food they were reared on and sleep was monitored for 2 days. On the morning of day 3 , flies were placed into tubes containing $1 \%$ agar and monitored for $18 \mathrm{~h}$. the flies were then placed back into Trikinetics tubes with food. For time-restricted feeding, flies were housed in vials on standard food between 8 am and $5 \mathrm{pm}$. At $5 \mathrm{pm}$, flies were transferred to vials containing $1 \%$ agar until 8 am the next morning when they were transferred to a new vial containing food. Flies underwent this protocol for 7 days. After 7 days, flies were individually placed into Trikinetics tubes containing standard food where they were allowed to eat ad lib. Siblings that were maintained in vials with standard food available ad lib and flipped at the same times as their restricted counterparts served as treatment controls

\section{Social Enrichment}

Social enrichment was performed as previously described [51]. Briefly, flies were housed in groups of 20 until 3-4 day old. Then, flies were separated in isolated or enriched groups. Isolated flies were transferred in individual $65 \mathrm{~mm}$ tubes. Enriched flies were pooled in groups of 50 flies for 5 days.

\section{Courtship Conditioning}

Training for naïve males was based on previously described methods [10]. For LTM, a spaced training protocol consisting of three 1-hour training sessions with a mated female, each separated by one hour was employed. For massed training protocol that does not induce LTM, a single 3h pairing with a mated female was employed.

\section{Live Brain Imaging}

Flies were chilled for approximately 5 minutes prior to pinning them onto a sylgaard dissection dish. Brains were dissected in calcium-free HL3 and then transferred onto a poly-lysine treated dish (35 3 $10 \mathrm{~mm}$ Falcon polystyrene) containing $3 \mathrm{ml}$ of $1.5 \mathrm{mM}$ calcium HL3. Two to four brains were assayed concurrently, typically untreated controls vs a comparison group (e.g. sleep deprived, starved, etc). Image capture was done using an Olympus BX61 and $\mathrm{x}, \mathrm{y}, \mathrm{z}$ stage movements were set via SLIDEBOOK 5.0 (Intelligent Imaging Innovations), which controlled a Prior H105Plan Power Stage through a Prior ProScanll. Multiple YFP/CFP ratio measurements were recorded in sequence from each brain in the dish. Following baseline measurements, $1 \mathrm{ml}$ of saline containing either AstA or DA, was added to the bath (dilution factor of 1/4). We used synthetic AstA (Neo-MPS) and dopamine (Sigma-Aldrich). Crustacean cardioactive peptide (CCAP), drosophila myosuppressin (DMS), allatostatin C (astA C), proctolin, TPAEDFMRFamide, corticotropin-releasing factor-like diuretic hormone 44 (DH44), Tachykinin 1, Tachykinin 3, short neuropeptide F (sNPF), adipokinetic hormone $(\mathrm{AKH})$, corazonin, and melatonin were kindly gifted by Paul Taghert (Washington University in St. Louis). For further details see [42, 43]. For experiment using P2X2, 1 mM ATP was used to activate the P2X2 receptor.

\section{Immunocytochemistry}

Flies were fixed in 4\% PFA, brains were dissected in ice cold PBS and incubated overnight with the following primary antibodies: mouse anti-AstA, (5F10, 1:2 dilution, Hybridoma Bank, University of 
lowa), chicken anti-GFP (GFP-1020; 1:1000, Aves Lab), rabbit anti-dsRed (Living Colors DsRed Polyclonal Antibody, 1:250, Clontech). Secondary antibodies were Alexa 488, 594 and 633 conjugated at a dilution 1:200. Brains were mounted on polylysine treated slides in Vectashield $\mathrm{H}$ 1000 mounting medium. Confocal stacks were acquired with a $0.5 \mu \mathrm{m}$ slice thickness using an Olympus FV1200 laser scanning confocal microscope and processed using ImageJ.

\section{Statistics}

All comparisons were done using a Student's T-test or, if appropriate, ANOVA and subsequent planned comparisons using modified Bonferroni test unless otherwise stated. Note that a significant omnibus- $\mathrm{F}$ is not a requirement for conducting planned comparisons [97]. All statistically different groups are defined as ${ }^{*} \mathrm{P}<0.05$.

\section{Figure legends.}

Figure 1: Sleep-promoting R23E10 neurons respond to AstA. a) Confirmation of R23E10GAL4>UAS-GFP dFB projections (blue arrow). b-c) R23E10-GAL4>UAS-dTrpA1 showed a significant increase in sleep at $31^{\circ} \mathrm{C}$ (red) compared to siblings maintained at $25^{\circ} \mathrm{C}$ (blue; $\mathrm{n}=16$ /group). d) Schematic of high-throughput Epac imaging. e,f) Normalized FRET ratio in R23E10GAL4>UAS-Epac1-camps in response to DA $\left(3 \times 10^{-5} \mathrm{M}\right)$ and AstA $\left(1 \mathrm{e}^{-6} \mathrm{M}\right)(\mathrm{n}=6-7$ cells/condition). $\mathbf{g})$ $\%$ change in FRET ratio in R23E10-GAL4>UAS-Epac1-camps following the application of neuroactive compounds ( $n=6-21$ cells/condition). $h$ ) TTX (1e-7M) does not prevent the response of R23E10>UAS-Epac1-camps to bath applied AstA (1 $\left.\mathrm{e}^{-6} \mathrm{M}\right)$ ( $\mathrm{n}=4-6$ cells/condition). Knocking down AstAR1 attenuates the response of R23E10 neurons to AstA (red trace; $\mathrm{n}=6$ ). i) Quantification of $\mathrm{H}$ ( $p<0.05$, modified Bonferoni test). j) Confocal stack of an AstA-GAL4>UAS-GFP fly brain stained with anti-GFP j') Anti-AstA (magenta) antibody. j') A merge image. k) Single optical section $(0.5 \mu \mathrm{m})$ of a R23E10-LexA>LexAop-GFP, AstA-GAL4>UAS-RFP fly brain stained with anti-GFP k') Anti-RFP (magenta) k") A merge image. I) Application of $1 \mathrm{mM}$ ATP induced a decrease in cAMP levels in $R 2310$ cells when the P2X2 receptor was expressed in AstA-GAL4 expressing neurons (blue trace), but not in control lines lacking the P2X2 receptor (red trace). $\mathrm{m}$ ) Quantification of I. Error bars represent standard error of the mean (SEM).

\section{Figure 2: Knocking down AstAR1 and AstAR2 in R23E10 neurons increases sleep.}

a) Sleep in minutes per hour b) Total sleep and c) daytime sleep-bout duration are increased when AstA-R1 is knocked down in R23E10 neurons compared with both UAS-Dcr2, R23E10-GAL4/+ and AstA-R $1^{R N A i} /+$ parental controls ( $\mathrm{n}=16 /$ condition, ${ }^{*} \mathrm{p}<0.05$ modified Bonferroni test). d) Waking activity is not different between UAS-Dcr2, R23E10-GAL4/+> AstA-R1RNAi/+ experimental flies and both UASDcr2, R23E10-GAL4/+ and AstA-R1RNAi/+ controls ( $\mathrm{n}=16 /$ condition, $\mathrm{p}>0.05$, modified Bonferroni test). e) Sleep in minutes per hour $\mathbf{f}$ ) Total sleep and $\mathbf{g}$ ) daytime sleep bout duration are increased when AstA-R2 is knocked down in R23E10 neurons compared with both UAS-Dcr2, R23E10-GAL4/+ and AstA-R2RNAi/+ parental controls ( $\mathrm{n}=16 /$ condition, ${ }^{*} \mathrm{p}<0.05$ modified Bonferroni test). $\mathrm{h}$ ) Waking activity is significantly increased in UAS-Dcr2, R23E10-GAL4/+> AstA-R2RNAi/+ experimental flies compared to both UAS-Dcr2, R23E10-GAL4/+ and AstA-R2RNAi/+ controls ( $\mathrm{n}=16 /$ condition, $\mathrm{p}<0.05$, modified Bonferroni test). i) Total sleep is not changed when Goa47A levels are reduced in R23E10 neurons, 
but independently knocking down Gia65A, G $\beta 5, G \beta 13 F, G \beta 76 C$ and $G \gamma 1$ in R23E10 cells increase total sleep compared with parental controls $\left(n=16 /\right.$ condition; $\left.{ }^{*}<<0.05\right)$. Error bars represent SEM.

Figure 3: R55B01 neurons respond to Allatostatin-A. a-b) R55B01-GAL4>UAS-dTrpA1 flies showed a significant increase in sleep at $31^{\circ} \mathrm{C}$ (red) compared to siblings maintained at $25^{\circ} \mathrm{C}$ (blue; $\mathrm{n}=16 /$ group). c) Expression pattern of R55B01-GAL4>UAS-GFP (blue arrow indicates the location of dFB). d) Normalized FRET ratio in R55B01>UAS-Epac1-camps in response to 1e-6 M AstA ( $\mathrm{n}=23$ cells). e) Normalized FRET ratio in R55B01>UAS-Epac1-camps to $3 e^{-5} \mathrm{M}$ DA $(\mathrm{n}=10)$. f) Box plot comparing the response properties of R23E10>Epac and R55B01>Epac neurons to $3 e^{-5} \mathrm{M} \mathrm{DA}$. The bottom and top of each box represents the first and third quartile, and the horizontal line dividing the box is the median. The whiskers represent the minimum and maximum individual cell responses. $n=68$ cells for R23E10 and $\mathrm{n}=115$ cells for R55B01. g,h) Knocking down AstAR1 or AstAR2 in R55B01 neurons increases sleep; Sleep in minutes per hour in R55B01-GAL4>AstAR1RNAi and R55B01GAL4>AstAR2RNAi ( $\mathrm{n}=16 /$ condition). Error bars represent SEM.

Figure 4: Sleep-promoting neurons integrate a variety of relevant stimuli. a,b) Response of R23E10 neurons in young (0-1 day old) and adult (6-8 day old) flies in response to Allatostatin-A (10${ }^{6}$ M) $(n=13,22$ cells $)$ or Dopamine $\left(3 e^{-5} M\right)(n=15,14$ cells). Quantification of traces in Figure 4 can be found in Figure S7. c,d) Response of R23E10 neurons in spontaneously short sleeping flies ( $<400 \mathrm{~min} /$ day) and normal sleeping siblings (600-900min/day) (AstA, $n=18,20$ cells) and (Dopamine, $\mathrm{n}=12,19$ cells). e,f) Response of R23E10 neurons following $12 \mathrm{~h}$ Sleep deprivation compared to untreated siblings (AstA, $\mathrm{n}=17,17$ cells) and (Dopamine, $\mathrm{n}=29,26$ cells). g,h) Response of R23E10 neurons following $18 \mathrm{~h}$ starvation compared to untreated siblings; (Ast $A, n=20,14$ cells) and (Dopamine, $\mathrm{n}=23,16$ cells). $\mathrm{i}, \mathrm{j})$ Response of R23E10 neurons following social enrichment compared to isolated siblings;(AstA, $\mathrm{n}=9,9$ cells) and (Dopamine, $\mathrm{n}=12,8$ cells). $\mathbf{k}, \mathbf{l}$ ) Response of R23E10 neurons following spaced training compared to naïve controls (AstA, $n=20,10$ cells) and (Dopamine, $\mathrm{n}=25,10$ cells). $\mathrm{m}$ ) Sleep is increased in R23E10-GAL4>CaLexA flies following a spaced courtship training ( $n=10$ per group, $p<0.05$ ). $n$ ) Representative confocal stack of the brains of a naïve (top) and spaced trained (bottom) R23E10-GAL4>CaLexA flies stained with anti-GFP antibody. Flies were dissected on the day after courtship conditioning. o) Quantification of GFP staining intensity in R23E10 neurons in naïve and spaced trained R23E10-GAL4>CaLexA flies ( $\mathrm{n}=107$ neurons for naïve and 100 neurons for trained).

Figure 5 Time-restricted feeding increases sleep via the Dop1R1. a) Protocol for time-restricted feeding b,c) During ad lib feeding, sleep in R23E10>Dop $1 R 1^{R N A i}$ and $R 55 B 01>D o p 1 R 1^{R N A i}$ flies does not differ from $R 23 E 10 /+$, Dop 1R1 RNAi/+ or R55B01/+ parental controls ( $\mathrm{n}=13-16$ flies/group ANOVA for Genotype $F[2,42]=2.8, p=0.07$ and ANOVA for Genotype $F[2,41]=1.9, p=0.15$ for R23E10 and R55B01 respectively. d) Daytime sleep was not altered in either $R 23 E 10>D o p 1 R 1^{R N A i}$ or $R 55 B 01>D o p 1 R 1^{R N A i}$ flies compared to both parental controls (ANOVA for Genotype $F[2,42]=2.8$, $\mathrm{p}=0.02$ and $\mathrm{F}[2,41]=2.9, \mathrm{p}=0.06,{ }^{*} \mathrm{p}<0.05$ Modified Bonferroni Test e) Nighttime sleep was not changed in either $R 23 E 10>D o p 1 R 1^{R N A i}$ or $R 55 B 01>D o p 1 R 1^{R N A i}$ flies compared to parental controls (ANOVA for Genotype $F[2,42]=0.9, p=0.40$ and ANOVA for Genotype $F[2,41]=0.79, p=0.46,{ }^{*} p<0.05$ Modified Bonferoni Test. $\mathbf{f , g}$ ) Following time-restricted feeding, sleep is increased in $R 23 E 10>D o p 1 R 1^{R N A i}$ and R55B01>Dop1R1 RNAi flies compared to R23E10/+, Dop1R1 RNAi/+ or R55B01/+ parental controls ( $\mathrm{n}=13-16$ flies/group ANOVA for Genotype $F[2,40]=68.8, p=9.9^{\mathrm{eE}-16}$ and 
ANOVA for Genotype F[2,35]=38.1.8, $\mathrm{p}=8.1^{\mathrm{eE}-10}$ for R23E10 and R55B01 respectively. $\mathbf{h}$ ) Daytime sleep was significantly increased in $R 23 E 10>D o p 1 R 1^{R N A i}$ and $R 55 B 01>D o p 1 R 1^{R N A i}$ flies following time restricted feeding (ANOVA for Genotype $F[2,40]=13.6, p=2.96^{\mathrm{E}-05}$ and $\mathrm{F}[2,35]=30.5, p=2.07^{\mathrm{E}-08}$, ${ }^{*} \mathrm{p}<0.05$ Modified Bonferroni Test i) Nighttime sleep was not changed in either R23E10>Dop 1R1RNAi or R55B01>Dop1R1 RNAi flies compared to parental controls (ANOVA for Genotype $F[2,40]=11.41$, $\mathrm{p}=0.0 .0001$ and ANOVA for Genotype $\mathrm{F}[2,35]=8.9, \mathrm{p}=0.0007,{ }^{*} \mathrm{p}<0.05$ Modified Bonferoni Test. Error bars represent SEM

Figure 6 Starvation alters recovery sleep and the response properties of sleep promoting neurons. a-b) Sleep profiles in $R 23 E 10>D o p 1 R 1^{R N A i}, R 55 B 01>D o p 1 R 1^{R N A i}$ flies and their parental controls R23E10/+, Dop1R1RNAi/+ and R55B01/+ during baseline, $18 \mathrm{~h}$ of starvation and three days of recovery ( $\mathrm{n}=13-16$ flies/group). $\mathbf{c}, \mathrm{d}$ ) During baseline, no changes in daytime or nighttime sleep were

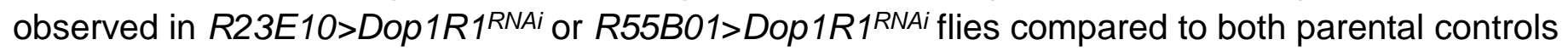
(Daytime: ANOVA $F[2,36]=8.1, p=0.001$ and $F[2,38]=2.26, p=0.11$ ), (Nighttime: ANOVA $F[2,36]=1.5$, $\mathrm{p}=0.22$ and ANOVA F[2,38] $=1.6, \mathrm{p}=0.20$, ${ }^{*} \mathrm{p}<0.05$ Modified Bonferoni Test. e) On recovery Day 3 , daytime sleep is increased in $R 23 E 10>D o p 1 R 1^{R N A i}$ and $R 55 B 01>D o p 1 R 1^{R N A i}$ flies compared to $R 23 E 10 /+$, Dop1R1RNAi + or R55B01/+ parental controls (ANOVA F[2,36] $=9.1, p=0.0006$ and $\mathrm{F}[2,38]=12.1, \mathrm{p}=8.43^{\mathrm{E}-05}$. f) Nighttime sleep is not changed in R23E10>Dop1R RNAi $^{\mathrm{N}}$ and R55B01>Dop1R1RNAi flies compared to R23E10/+, Dop1R1RNAi/+ or R55B01/+ parental controls (ANOVA $F[2,36]=3.9, p=0.02$ and $F[2,38]=0.09, p=0.9{ }^{*} p<0.05$ Modified Bonferoni Test. Error bars represent SEM

Figure 7 Starvation alters the response properties of sleep promoting neurons. a) R23E10 cells expressing the cAMP sensor Epac1-camps respond to $3 \times 10-5 \mathrm{M}$ DA (black line; $n=22$ neurons); the response is dramatically reduced in $R 23 E 10>E p a c ; D o p 1 R 2^{R N A i}$ (white line; $\mathrm{n}=25$ neurons) and partially restored during recovery from $18 \mathrm{~h}$ of starvation (grey line; $\mathrm{n}=29$ neurons). b) Quantification of a; $F[2,73]=7.7, p=0.0009{ }^{*} p<0.05$ Modified Bonferoni Test. c) The response of R55B01 $>E p a c$ (black; $\mathrm{n}=13$ ) and R55B01>Epac; Dop1R2RNAi (white; $\mathrm{n}=19$ ) neurons to dopamine is very low; following recovery from starvation, the response of R55B01 neurons to DA increased (grey line; $n$ $=20)$. d) Quantification of $c ; F[2,49]=9.9, p=0.0002{ }^{*} p<0.05$ Modified Bonferoni Test. Error bars represent SEM

\section{Author Contributions}

S.D., M.K.K., B.V.S. and P.J.S. designed the experiments and wrote the paper. S.D., M.K.K., L.C., and P.J.S. performed the experiments. S.D., M.K.K., L.C., and P.J.S. analyzed the data. The funders had no role in study design, data collection and analysis, decision to publish, or preparation of the manuscript

\section{Acknowledgments}

We thank Gerald Rubin, Arnim Jenett, Jin Wang, Ori Shafer and Paul Taghert for sharing reagents and flies. Funding: This work was supported by NIH grants 5R01NS051305-14 and 5R01NS076980- 
08 to PJS. The confocal facility is supported by NIH shared instrument grant S1OD21629-01A1. Competing Interests: The authors declare no competing interests.

\section{References}

1. Allada, R., C. Cirelli, and A. Sehgal, Molecular Mechanisms of Sleep Homeostasis in Flies and Mammals. Cold Spring Harb Perspect Biol, 2017.

2. $\quad$ Siegel, J.M., Sleep viewed as a state of adaptive inactivity. Nat Rev Neurosci, 2009. 10(10): p. 747-53.

3. Klose, M.K. and P.J. Shaw, Sleep drive reconfigures wake-promoting clock circuitry to regulate adaptive behavior. PLoS Biol, 2021. 19(6): p. e3001324.

4. Donlea, J., et al., Foraging alters resilience/vulnerability to sleep disruption and starvation in Drosophila. Proc Natl Acad Sci U S A, 2012. 109(7): p. 2613-8.

5. Keene, A.C., et al., Clock and cycle limit starvation-induced sleep loss in Drosophila. Curr Biol, 2010. 20(13): p. 1209-15.

6. Lesku, J.A., et al., Adaptive sleep loss in polygynous pectoral sandpipers. Science, 2012. 337(6102): p. $1654-8$.

7. Banks, S., et al., The Maintenance of Wakefulness Test and driving simulator performance. Sleep, 2005. 28(11): p. 1381-5.

8. Akerstedt, T., et al., Impaired alertness and performance driving home from the night shift: a driving simulator study. J Sleep Res, 2005. 14(1): p. 17-20.

9. Dissel, S., et al., Sleep restores behavioral plasticity to Drosophila mutants. Curr Biol, 2015. 25(10): p. $1270-81$.

10. Donlea, J.M., et al., Inducing sleep by remote control facilitates memory consolidation in Drosophila. Science, 2011. 332(6037): p. 1571-6.

11. Gerstner, J.R., et al., Fatty-acid binding proteins modulate sleep and enhance long-term memory consolidation in Drosophila. PLoS One, 2011. 6(1): p. e15890.

12. Stickgold, R. and M.P. Walker, Sleep-dependent memory triage: evolving generalization through selective processing. Nat Neurosci, 2013. 16(2): p. 139-45.

13. Aso, Y., et al., The neuronal architecture of the mushroom body provides a logic for associative learning. Elife, 2014. 3: p. e04577.

14. Luan, H., et al., The Drosophila Split Gal4 System for Neural Circuit Mapping. Front Neural Circuits, 2020. 14: p. 603397.

15. Dolan, M.J., et al., Facilitating Neuron-Specific Genetic Manipulations in Drosophila melanogaster Using a Split GAL4 Repressor. Genetics, 2017. 206(2): p. 775-784.

16. Gnerer, J.P., K.J. Venken, and H.A. Dierick, Gene-specific cell labeling using MiMIC transposons. Nucleic Acids Res, 2015. 43(8): p. e56.

17. Deng, B., et al., Chemoconnectomics: Mapping Chemical Transmission in Drosophila. Neuron, 2019. 101(5): p. 876-893 e4.

18. Liu, S., et al., Sleep Drive Is Encoded by Neural Plastic Changes in a Dedicated Circuit. Cell, 2016. 165(6): p. 134760.

19. Pimentel, D., et al., Operation of a homeostatic sleep switch. Nature, 2016. 536(7616): p. 333-7.

20. Sitaraman, D., et al., Propagation of Homeostatic Sleep Signals by Segregated Synaptic Microcircuits of the Drosophila Mushroom Body. Curr Biol, 2015. 25(22): p. 2915-27.

21. May, C.E., et al., Dietary sugar inhibits satiation by decreasing the central processing of sweet taste. Elife, 2020. 9.

22. Musso, P.Y., et al., Closed-loop optogenetic activation of peripheral or central neurons modulates feeding in freely moving Drosophila. Elife, 2019. 8.

23. Landayan, D., et al., Thirst interneurons that promote water seeking and limit feeding behavior in Drosophila. Elife, 2021. 10.

24. Bentzur, A., et al., Early Life Experience Shapes Male Behavior and Social Networks in Drosophila. Curr Biol, 2021. 31(3): p. 486-501 e3. 
25. Ni, J.D., et al., Differential regulation of the Drosophila sleep homeostat by circadian and arousal inputs. Elife, 2019. 8.

26. Donlea, J.M., et al., Recurrent Circuitry for Balancing Sleep Need and Sleep. Neuron, 2018. 97(2): p. 378-389 e4.

27. Chen, J., et al., Allatostatin A Signalling in Drosophila Regulates Feeding and Sleep and Is Modulated by PDF. PLoS Genet, 2016. 12(9): p. e1006346.

28. Thimgan, M.S., et al., The perilipin homologue, lipid storage droplet 2, regulates sleep homeostasis and prevents learning impairments following sleep loss. PLoS Biol, 2010. 8(8).

29. Linford, N.J., et al., Gustatory and metabolic perception of nutrient stress in Drosophila. Proc Natl Acad Sci U S A, 2015. 112(8): p. 2587-92.

30. Sareen, P.F., L.Y. McCurdy, and M.N. Nitabach, A neuronal ensemble encoding adaptive choice during sensory conflict in Drosophila. Nat Commun, 2021. 12(1): p. 4131.

31. Cheriyamkunnel, S.J., et al., A neuronal mechanism controlling the choice between feeding and sexual behaviors in Drosophila. Curr Biol, 2021.

32. Lin, S., B. Senapati, and C.H. Tsao, Neural basis of hunger-driven behaviour in Drosophila. Open Biol, 2019. 9(3): p. 180259.

33. Miroschnikow, A., P. Schlegel, and M.J. Pankratz, Making Feeding Decisions in the Drosophila Nervous System. Curr Biol, 2020. 30(14): p. R831-R840.

34. Senapati, B., et al., A neural mechanism for deprivation state-specific expression of relevant memories in Drosophila. Nat Neurosci, 2019. 22(12): p. 2029-2039.

35. Liu, Q., et al., Two dopaminergic neurons signal to the dorsal fan-shaped body to promote wakefulness in Drosophila. Curr Biol, 2012. 22(22): p. 2114-23.

36. Ueno, T., et al., Identification of a dopamine pathway that regulates sleep and arousal in Drosophila. Nat Neurosci, 2012. 15(11): p. 1516-23.

37. Hergarden, A.C., T.D. Tayler, and D.J. Anderson, Allatostatin-A neurons inhibit feeding behavior in adult Drosophila. Proc Natl Acad Sci U S A, 2012. 109(10): p. 3967-72.

38. Donlea, J.M., D. Pimentel, and G. Miesenbock, Neuronal machinery of sleep homeostasis in Drosophila. Neuron, 2014. 81(4): p. 860-72.

39. Kempf, A., et al., A potassium channel beta-subunit couples mitochondrial electron transport to sleep. Nature, 2019. 568(7751): p. 230-234.

40. Sakurai, A., et al., Alteration in information flow through a pair of feeding command neurons underlies a form of Pavlovian conditioning in the Drosophila brain. Curr Biol, 2021.

41. Holland, C., Sleep homeostasis in Drosophila: a window on the vital function of sleep. Bioscience Horizons: The International Journal of Student Research, 2018. 11.

42. Klose, M., et al., Functional PDF Signaling in the Drosophila Circadian Neural Circuit Is Gated by Ral A-Dependent Modulation. Neuron, 2016. 90(4): p. 781-94.

43. Shafer, O.T., et al., Widespread receptivity to neuropeptide PDF throughout the neuronal circadian clock network of Drosophila revealed by real-time cyclic AMP imaging. Neuron, 2008. 58(2): p. 223-37.

44. Nässel, D.R., D. Pauls, and W. Huetteroth, Neuropeptides in modulation of Drosophila behavior: how to get a grip on their pleiotropic actions. Curr Opin Insect Sci, 2019. 36: p. 1-8.

45. Nässel, D.R., Substrates for Neuronal Cotransmission With Neuropeptides and Small Molecule Neurotransmitters in Drosophila. Front Cell Neurosci, 2018. 12: p. 83.

46. Lima, S.Q. and G. Miesenbock, Remote control of behavior through genetically targeted photostimulation of neurons. Cell, 2005. 121(1): p. 141-52.

47. Wang, S., et al., Differential intracellular signaling of the GalR1 and GaIR2 galanin receptor subtypes. Biochemistry, 1998. 37(19): p. 6711-7.

48. Troup, M., et al., Acute control of the sleep switch in Drosophila reveals a role for gap junctions in regulating behavioral responsiveness. Elife, 2018. 7.

49. Jenett, A., et al., A GAL4-driver line resource for Drosophila neurobiology. Cell Rep, 2012. 2(4): p. 991-1001.

50. Seugnet, L., et al., D1 receptor activation in the mushroom bodies rescues sleep-loss-induced learning impairments in Drosophila. Curr Biol, 2008. 18(15): p. 1110-7.

51. Ganguly-Fitzgerald, I., J. Donlea, and P.J. Shaw, Waking experience affects sleep need in Drosophila. Science, 2006. 313(5794): p. 1775-81. 
52. Shaw, P.J., et al., Correlates of sleep and waking in Drosophila melanogaster. Science, 2000. 287(5459): p. 18347.

53. Kayser, M.S., Z. Yue, and A. Sehgal, A critical period of sleep for development of courtship circuitry and behavior in Drosophila. Science, 2014. 344(6181): p. 269-74.

54. Hendricks, J.C., et al., Rest in Drosophila is a sleep-like state. Neuron, 2000. 25(1): p. 129-38.

55. Dissel, S., et al., Differential activation of immune factors in neurons and glia contribute to individual differences in resilience/vulnerability to sleep disruption. Brain Behav Immun, 2015. 47: p. 75-85.

56. Seugnet, L., et al., Identifying sleep regulatory genes using a Drosophila model of insomnia. J Neurosci, 2009. 29(22): p. 7148-57.

57. Thimgan, M.S., et al., Identification of genes associated with resilience/vulnerability to sleep deprivation and starvation in Drosophila. Sleep, 2015. 38(5): p. 801-14.

58. Donlea, J.M., N. Ramanan, and P.J. Shaw, Use-dependent plasticity in clock neurons regulates sleep need in Drosophila. Science, 2009. 324(5923): p. 105-8.

59. Dag, U., et al., Neuronal reactivation during post-learning sleep consolidates long-term memory in Drosophila. Elife, 2019. 8.

60. Masuyama, K., et al., Mapping neural circuits with activity-dependent nuclear import of a transcription factor. J Neurogenet, 2012. 26(1): p. 89-102.

61. Jiang, Y., et al., A Genetic Screen To Assess Dopamine Receptor (DopR1) Dependent Sleep Regulation in Drosophila. G3 (Bethesda), 2016. 6(12): p. 4217-4226.

62. Gill, S., et al., Time-restricted feeding attenuates age-related cardiac decline in Drosophila. Science, 2015. 347(6227): p. 1265-9.

63. Chaix, A., et al., Sex-and age-dependent outcomes of 9-hour time-restricted feeding of a Western high-fat highsucrose diet in C57BL/6J mice. Cell Rep, 2021. 36(7): p. 109543.

64. Ulgherait, M., et al., Circadian autophagy drives iTRF-mediated longevity. Nature, 2021.

65. Himmelreich, S., et al., Dopamine Receptor DAMB Signals via Gq to Mediate Forgetting in Drosophila. Cell Rep, 2017. 21(8): p. 2074-2081.

66. Flores-Valle, A., P.J. Goncalves, and J.D. Seelig, Integration of sleep homeostasis and navigation in Drosophila. PLoS Comput Biol, 2021. 17(7): p. e1009088.

67. Coutanche, M.N., et al., The role of sleep in forming a memory representation of a two-dimensional space. Hippocampus, 2013.

68. Kirszenblat, L., et al., Sleep regulates visual selective attention in Drosophila. J Exp Biol, 2018. 221(Pt 24).

69. Krause, A.J., et al., The sleep-deprived human brain. Nat Rev Neurosci, 2017. 18(7): p. 404-418.

70. Beckwith, E.J. and A.S. French, Sleep in Drosophila and Its Context. Frontiers in Physiology, 2019. 10(1167).

71. Chouhan, N.S., et al., Availability of food determines the need for sleep in memory consolidation. Nature, 2021. 589(7843): p. 582-585.

72. Rechtschaffen, A., et al., Physiological correlates of prolonged sleep deprivation in rats. Science, 1983. 221(4606): p. 182-4.

73. Shaw, P.J., et al., Stress response genes protect against lethal effects of sleep deprivation in Drosophila. Nature, 2002. 417(6886): p. 287-91.

74. Shafer, O.T. and A.C. Keene, The Regulation of Drosophila Sleep. Curr Biol, 2021. 31(1): p. R38-r49.

75. Kim, J.H., et al., The voltage-gated potassium channel Shaker promotes sleep via thermosensitive GABA transmission. Commun Biol, 2020. 3(1): p. 174.

76. Parisky, K.M., et al., Reorganization of Sleep by Temperature in Drosophila Requires Light, the Homeostat, and the Circadian Clock. Curr Biol, 2016. 26(7): p. 882-92.

77. Tsuneoka, Y. and H. Funato, Cellular Composition of the Preoptic Area Regulating Sleep, Parental, and Sexual Behavior. Front Neurosci, 2021. 15: p. 649159.

78. Oh, J., et al., The role of co-neurotransmitters in sleep and wake regulation. Mol Psychiatry, 2019. 24(9): p. 12841295.

79. Svensson, E., et al., General Principles of Neuronal Co-transmission: Insights From Multiple Model Systems. Front Neural Circuits, 2018. 12: p. 117.

80. Yu, X., et al., Wakefulness Is Governed by GABA and Histamine Cotransmission. Neuron, 2015. 87(1): p. $164-78$.

81. Hökfelt, T., et al., Neuropeptide and Small Transmitter Coexistence: Fundamental Studies and Relevance to Mental IIIness. Front Neural Circuits, 2018. 12: p. 106. 
82. Croset, V., C.D. Treiber, and S. Waddell, Cellular diversity in the Drosophila midbrain revealed by single-cell transcriptomics. Elife, 2018. 7.

83. Tainton-Heap, L.A.L., et al., A Paradoxical Kind of Sleep in Drosophila melanogaster. Curr Biol, 2021. 31(3): p. 578-590.e6.

84. Tabuchi, M., et al., Clock-Generated Temporal Codes Determine Synaptic Plasticity to Control Sleep. Cell, 2018. 175(5): p. 1213-1227.e18.

85. Billimoria, C.P., et al., Neuromodulation of spike-timing precision in sensory neurons. J Neurosci, 2006. 26(22): p. 5910-9.

86. Dong, Y., J.P. Tyszkiewicz, and T.M. Fong, Galanin and galanin-like peptide differentially modulate neuronal activities in rat arcuate nucleus neurons. J Neurophysiol, 2006. 95(5): p. 3228-34.

87. Chung, S., et al., Identification of preoptic sleep neurons using retrograde labelling and gene profiling. Nature, 2017. 545(7655): p. 477-481.

88. Kohl, J., et al., Functional circuit architecture underlying parental behaviour. Nature, 2018. 556(7701): p. 326331.

89. Ma, Y., et al., Galanin Neurons Unite Sleep Homeostasis and a2-Adrenergic Sedation. Curr Biol, 2019. 29(19): p. 3315-3322.e3.

90. Hentze, J.L., et al., The Neuropeptide Allatostatin A Regulates Metabolism and Feeding Decisions in Drosophila. Sci Rep, 2015. 5: p. 11680.

91. Barf, R.P., et al., Increased food intake and changes in metabolic hormones in response to chronic sleep restriction alternated with short periods of sleep allowance. Am J Physiol Regul Integr Comp Physiol, 2012. 302(1): p. R112-7.

92. Yurgel, M.E., et al., Genetic dissection of sleep-metabolism interactions in the fruit fly. J Comp Physiol A Neuroethol Sens Neural Behav Physiol, 2015. 201(9): p. 869-77.

93. Bergmann, B.M., et al., Sleep deprivation in the rat: V. Energy use and mediation. Sleep, 1989. 12(1): p. 31-41.

94. Spiegel, K., et al., Effects of poor and short sleep on glucose metabolism and obesity risk. Nat Rev Endocrinol, 2009. 5(5): p. 253-61.

95. Berry, J.A., et al., Sleep Facilitates Memory by Blocking Dopamine Neuron-Mediated Forgetting. Cell, 2015. 161(7): p. 1656-67.

96. Melnattur, K., B. Zhang, and P.J. Shaw, Disrupting flight increases sleep and identifies a novel sleep-promoting pathway in Drosophila. Sci Adv, 2020. 6(19): p. eaaz2166.

97. Keppel, G., Design and Analysis a researcher's handbook 2nd ed. 1982, Englewood Cliffs, NJ Prentice-Hall 669. 
bioRxiv preprint doi: https://doi.org/10.1101/2021.11.05.467459; this version posted November 7, 2021. The copyright holder for this preprint (which was not certified by peer review) is the author/funder, who has granted bioRxiv a license to display the preprint in perpetuity. It is made available under aCC-BY-NC-ND 4.0 International license.

\section{Figure 1}

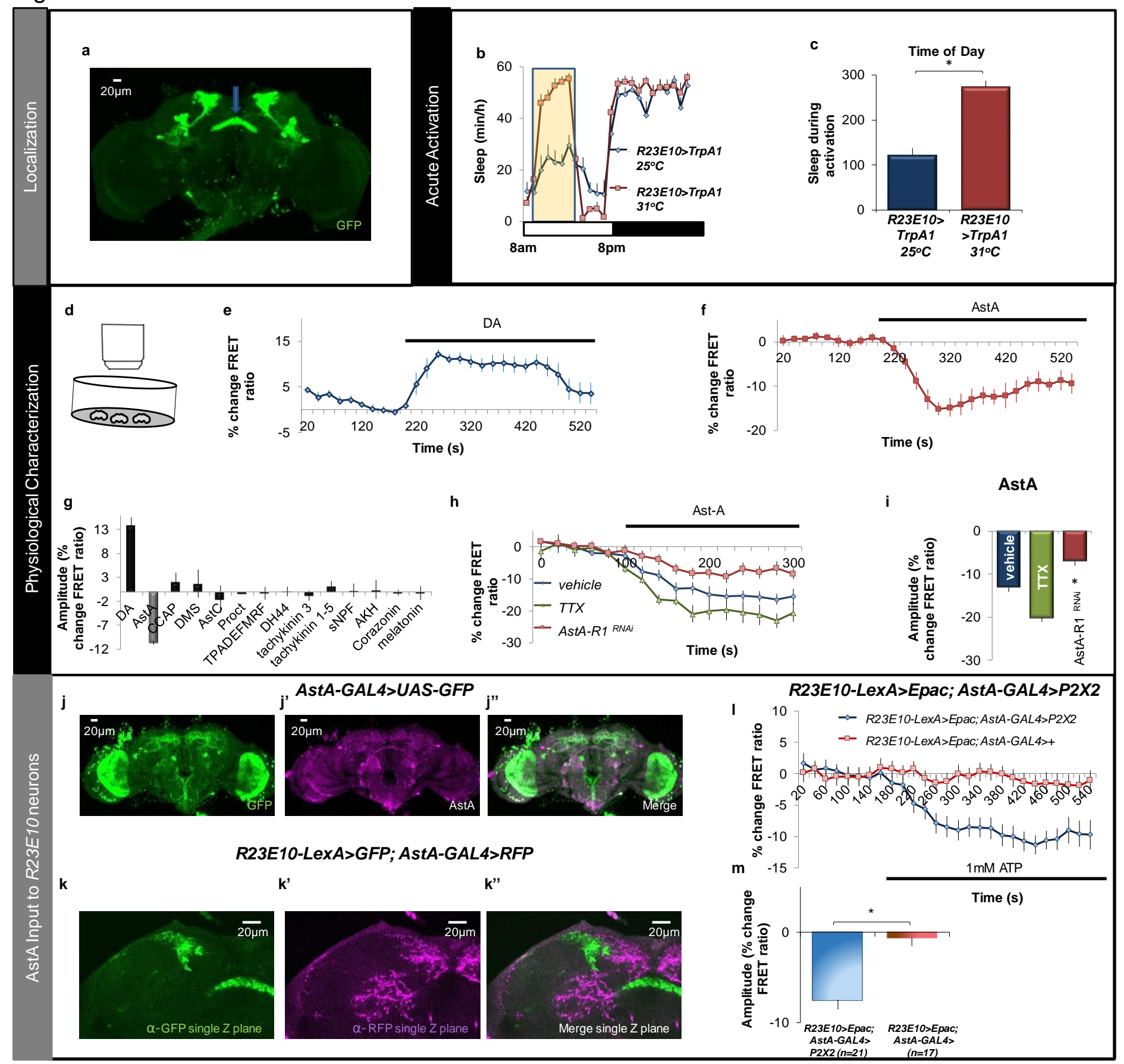


bioRxiv preprint doi: https://doi.org/10.1101/2021.11.05.467459; this version posted November 7, 2021. The copyright holder for this preprint (which was not certified by peer review) is the author/funder, who has granted bioRxiv a license to display the preprint in perpetuity. It is made available under aCC-BY-NC-ND 4.0 International license.

Figure 2

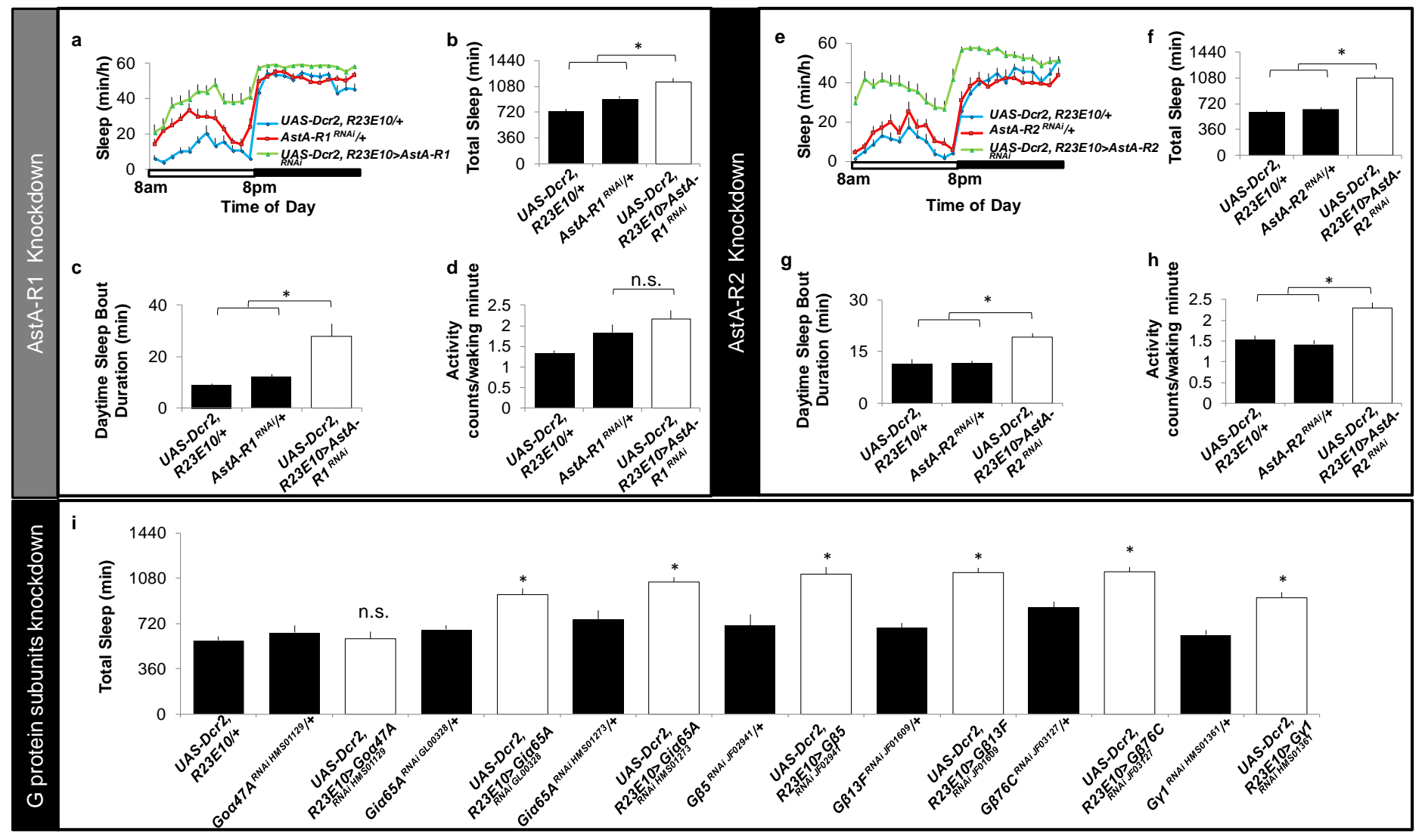


bioRxiv preprint doi: https://doi.org/10.1101/2021.11.05.467459; this version posted November 7, 2021. The copyright holder for this preprint (which was not certified by peer review) is the author/funder, who has granted bioRxiv a license to display the preprint in perpetuity. It is made available under aCC-BY-NC-ND 4.0 International license.

Figure 3
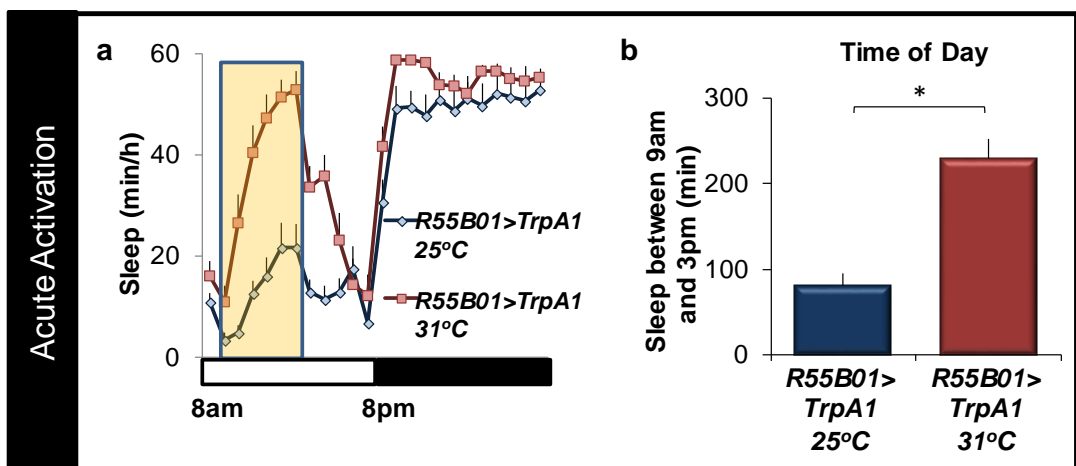

e

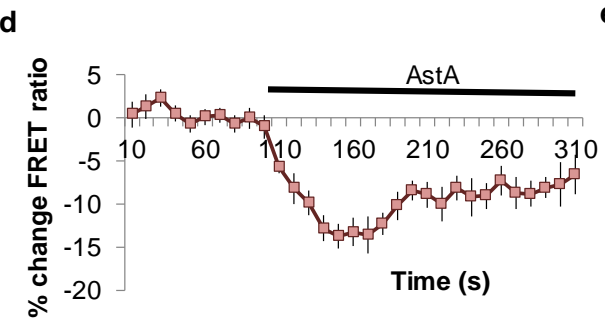

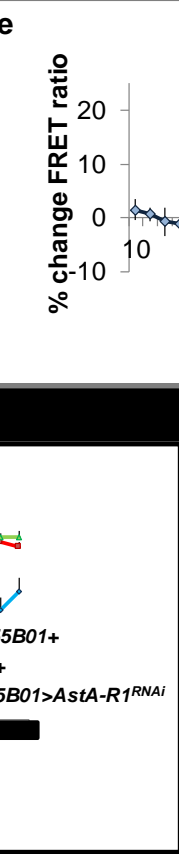

c

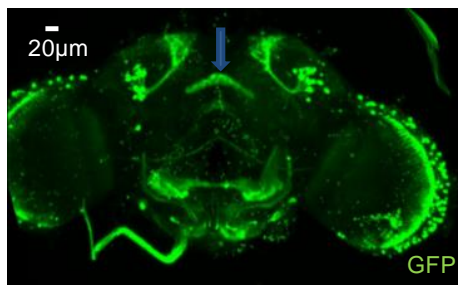

f

\section{AstAR1}

g

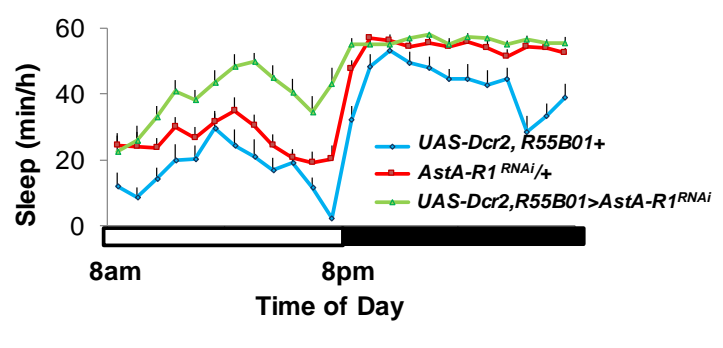

\section{AstAR2}

h

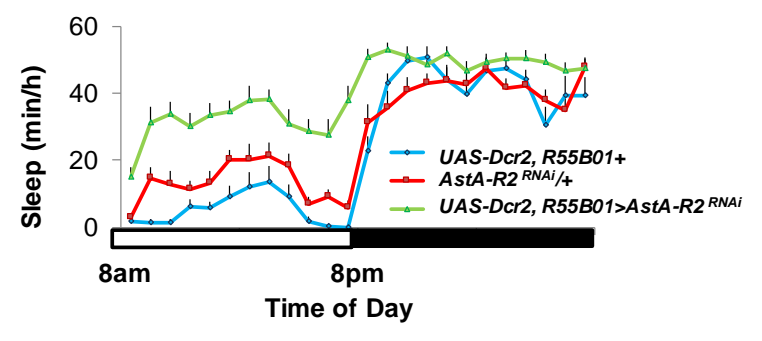


bioRxiv preprint doi: https://doi.org/10.1101/2021.11.05.467459; this version posted November 7, 2021. The copyright holder for this preprint (which was not certified by peer review) is the author/funder, who has granted bioRxiv a license to display the preprint in perpetuity. It is made available under aCC-BY-NC-ND 4.0 International license.

Figure 4

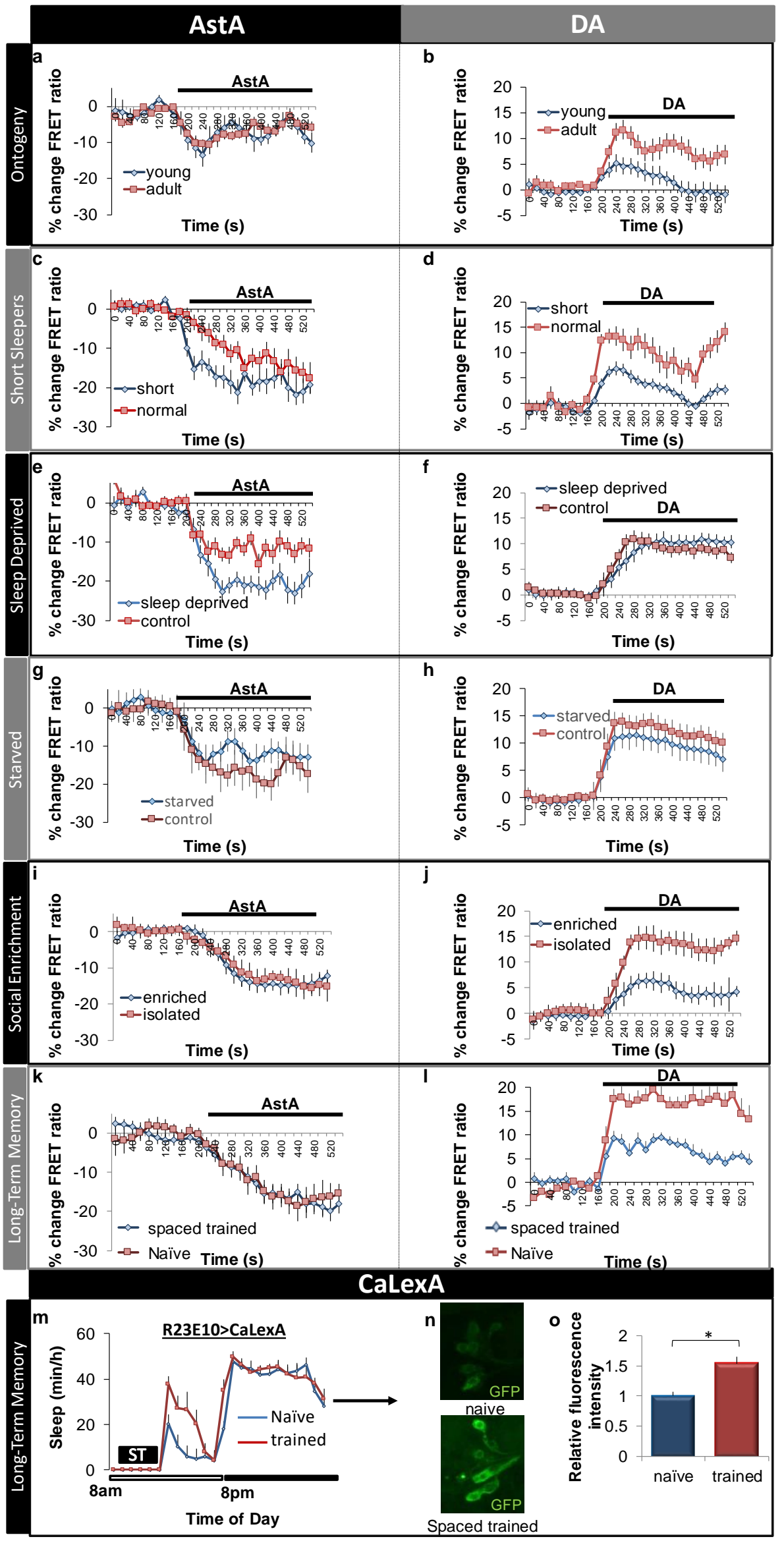


bioRxiv preprint doi: https://doi.org/10.1101/2021.11.05.467459; this version posted November 7, 2021. The copyright holder for this preprint (which was not certified by peer review) is the author/funder, who has granted bioRxiv a license to display the preprint in perpetuity. It is made available under aCC-BY-NC-ND 4.0 International license.

\section{Figure 5}




bioRxiv preprint doi: https://doi.org/10.1101/2021.11.05.467459; this version posted November 7, 2021. The copyright holder for this preprint (which was not certified by peer review) is the author/funder, who has granted bioRxiv a license to display the preprint in perpetuity. It is made available under aCC-BY-NC-ND 4.0 International license.

Figure 6
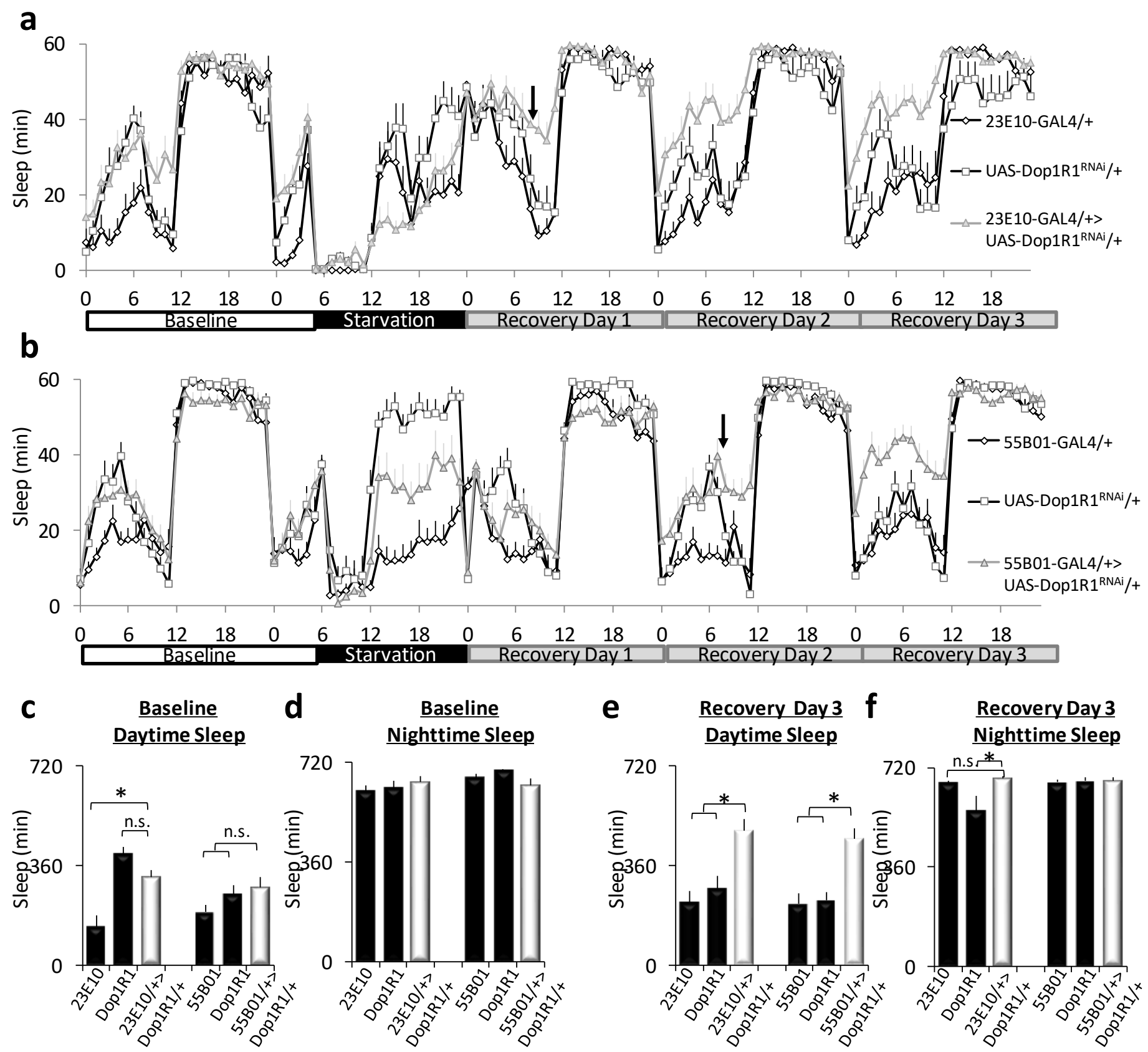
bioRxiv preprint doi: https://doi. org/10.1101/2021.11.05.467459. this version posted November 7, 2021. The copyright holder for this preprint (which was not certified by peer review) is the author/funder, who has granted bioRxiv a license to display the preprint in perpetuity. It is made available under aCC-BY-NC-ND 4.0 International license.

\section{Figure 7}

a

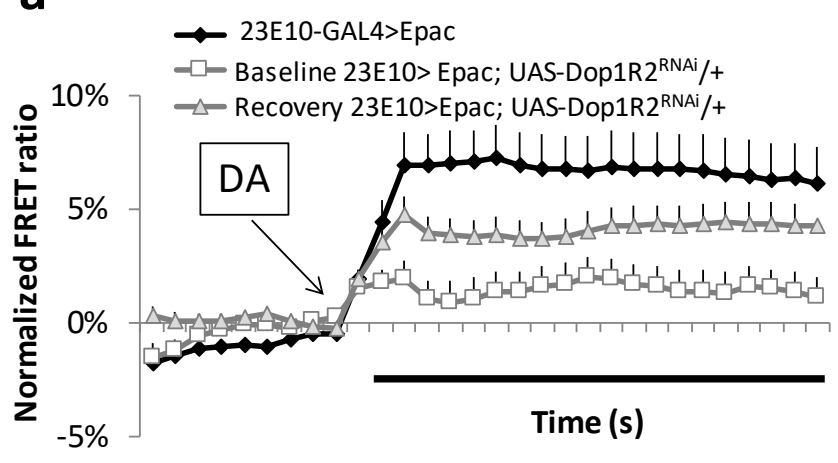

C

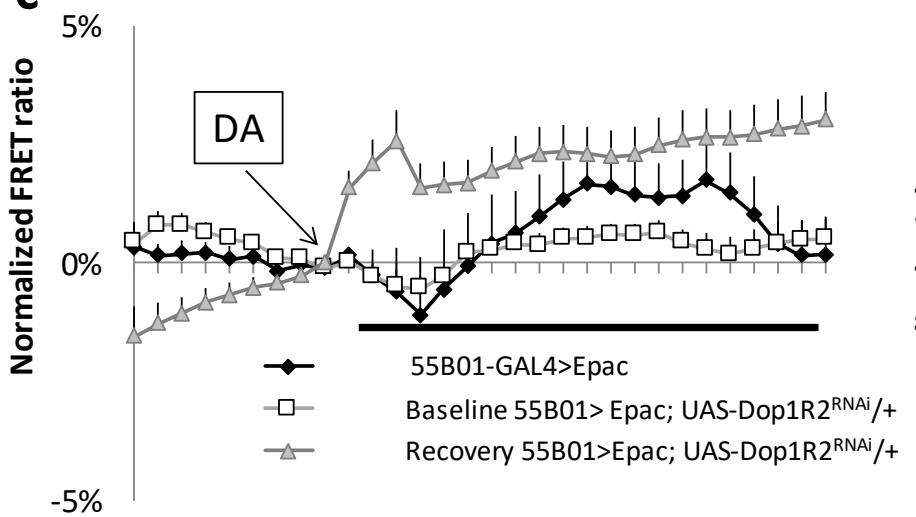

b

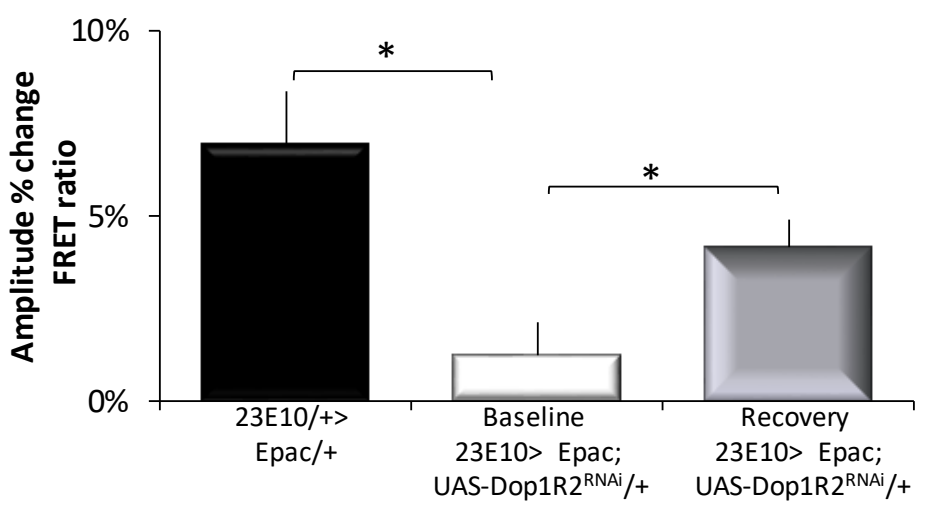

d

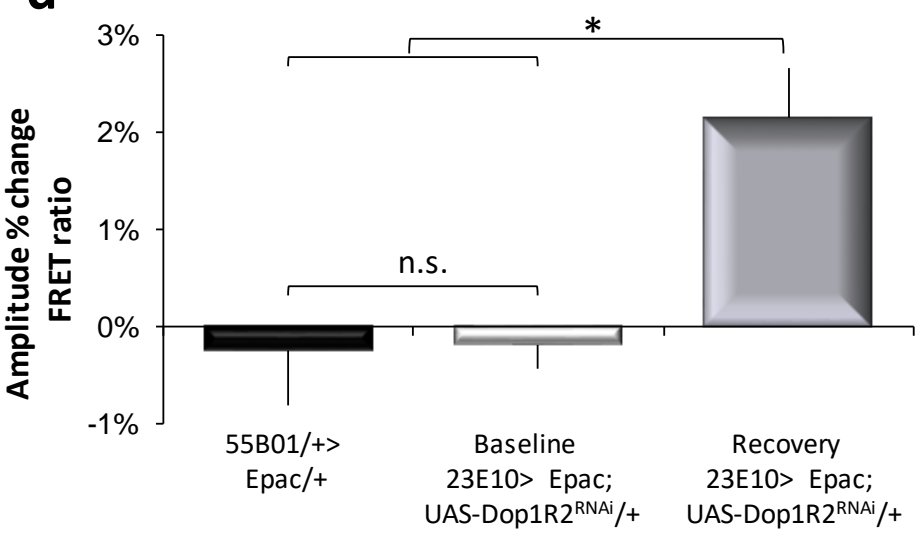


bioRxiv preprint doi: https://doi.org/10.1101/2021.11.05.467459; this version posted November 7, 2021. The copyright holder for this preprint (which was not certified by peer review) is the author/funder, who has granted bioRxiv a license to display the preprint in perpetuity. It is made available under aCC-BY-NC-ND 4.0 International license. 